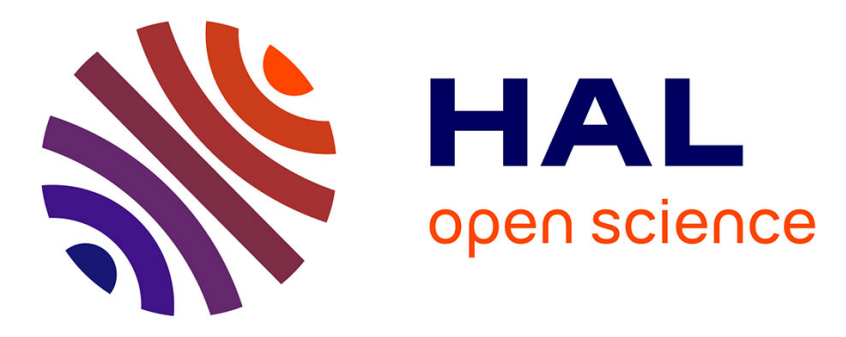

\title{
An extension of the Bus asteroid taxonomy into the near-infrared
}

Francesca E. Demeo, Richard P. Binzel, Stephen M. Slivan, Schelte J. Bus

\section{To cite this version:}

Francesca E. Demeo, Richard P. Binzel, Stephen M. Slivan, Schelte J. Bus. An extension of the Bus asteroid taxonomy into the near-infrared. Icarus, 2009, 202 (1), pp.160. 10.1016/j.icarus.2009.02.005 . hal-00545286

\author{
HAL Id: hal-00545286 \\ https://hal.science/hal-00545286
}

Submitted on 10 Dec 2010

HAL is a multi-disciplinary open access archive for the deposit and dissemination of scientific research documents, whether they are published or not. The documents may come from teaching and research institutions in France or abroad, or from public or private research centers.
L'archive ouverte pluridisciplinaire HAL, est destinée au dépôt et à la diffusion de documents scientifiques de niveau recherche, publiés ou non, émanant des établissements d'enseignement et de recherche français ou étrangers, des laboratoires publics ou privés. 


\section{Accepted Manuscript}

An extension of the Bus asteroid taxonomy into the near-infrared

Francesca E. DeMeo, Richard P. Binzel, Stephen M. Slivan, Schelte J. Bus

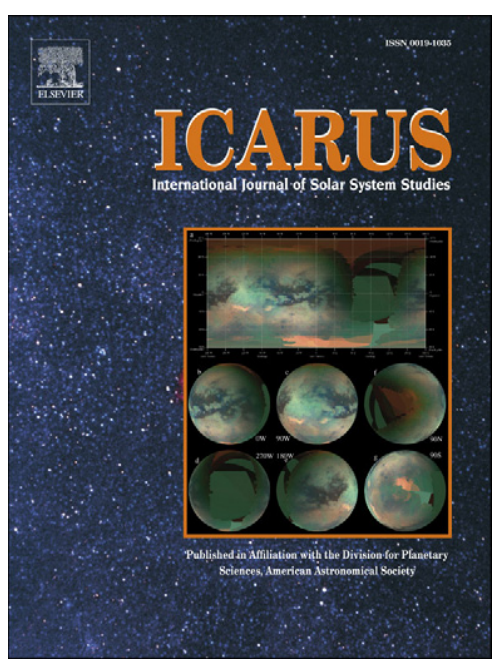

PII: $\quad$ S0019-1035(09)00055-4

DOI: $\quad$ 10.1016/j.icarus.2009.02.005

Reference: $\quad$ YICAR 8908

To appear in: Icarus

Received date: 30 October 2008

Revised date: 6 February 2009

Accepted date: 9 February 2009

Please cite this article as: F.E. DeMeo, R.P. Binzel, S.M. Slivan, S.J. Bus, An extension of the Bus asteroid taxonomy into the near-infrared, Icarus (2009), doi: 10.1016/j.icarus.2009.02.005

This is a PDF file of an unedited manuscript that has been accepted for publication. As a service to our customers we are providing this early version of the manuscript. The manuscript will undergo copyediting, typesetting, and review of the resulting proof before it is published in its final form. Please note that during the production process errors may be discovered which could affect the content, and all legal disclaimers that apply to the journal pertain. 


\section{An extension of the Bus asteroid taxonomy into the Near-Infrared}

Francesca E. DeMeo ${ }^{\text {a }}$, Richard P. Binzel ${ }^{\text {b }}$, Stephen M. Slivan ${ }^{\text {b }}$, and Schelte J. Bus ${ }^{c}$

${ }^{a}$ LESIA, Observatoire de Paris, F-92195 Meudon Principal Cedex, France

${ }^{\mathrm{b}}$ Department of Earth, Atmospheric, and Planetary Sciences, Massachusetts Institute of Technology, Cambridge, MA 02139

${ }^{\mathrm{c}}$ Institute for Astronomy, 640 N. Aohoku Place, Hilo, HI 96720

Number of pages: 65

Number of tables: 5

Number of figures: 15

Number of appendices: 4 
Proposed Running Head: An extension of the Bus asteroid taxonomy into the Near-Infrared

Please send Editorial Correspondence to: Francesca E. DeMeo LESIA, Observatoire de Paris F-92195 Meudon Principal Cedex, France

Email: francesca.demeo@obspm.fr

Phone: +33145077409

Fax: +33145077144 
ABSTRACT

The availability of asteroid spectral measurements extending to the near-infrared, resulting from the development of new telescopic instruments (such as SpeX; Rayner 2003), provides a new basis for classifying asteroid reflectance spectra. We present an asteroid taxonomy classification system based on reflectance spectrum characteristics for 371 asteroids measured over the wavelength range 0.45 to 2.45 microns. This system of 24 classes is constructed using principal component analysis, following most closely the visible wavelength taxonomy of Bus (1999), which itself builds upon the system of Tholen (1984). Nearly all of the Bus taxonomy classes are preserved, with one new class $(\mathrm{Sv})$ defined. For each class we present boundary definitions, spectral descriptions, and prototype examples. A flow chart method is presented for classifying newly acquired data spanning this wavelength range. When data are available only in the near-infrared range ( 0.85 to 2.45 microns), classification is also possible in many cases through an alternate flow chart process. Within our sample, several classes remain relatively rare: only 6 objects fall into the A-class; 349 Dembowska and 3628 Boznemcova reside as the only objects in their respective R- and O-classes. Eight Q-class objects are all near-Earth asteroids. We note 1904 Massevitch as an outer main-belt Vtype while 15 other V-type objects have inner main-belt orbits consistent with an association with Vesta.

Keywords:ASTEROIDS; SPECTROSCOPY 


\section{Introduction}

Taxonomic classification systems for asteroids have existed since there were enough data to distinguish meaningful groups. The first taxonomies were based on asteroid broad band filter colors such as Wood and Kuiper (1963) and Chapman et al. (1971) where they noted two separate types of objects denoted as "S" and "C". Taxonomies and their nomenclature grew and evolved as later taxonomies became based on higher resolution spectral data which reveal features offering clues to surface composition, age, and alteration. The most widely used taxonomies for asteroids currently are the Tholen taxonomy (1984) based on the Eight-Color Asteroid Survey data (ECAS, Zellner et al., 1985) and SMASSII spectral taxonomy (Bus, 1999; Bus and Binzel, 2002a,b) based on the SMASSII spectral dataset. For a review of the evolution of asteroid taxonomies see Bus (1999).

Both the Tholen and Bus taxonomies were based on Principal Component Analysis, a dimension-reducing technique first applied to the field of asteroid classification by Tholen (1984). Most previous asteroid taxonomies were based on visible data because only in the current decade has spectral data collection become widely available in the near-infrared for asteroids down to relatively faint $(\mathrm{V}=17)$ limiting magnitudes. The instrument SpeX on the NASA Infrared Telescope Facility (IRTF) has been crucial to increasing the library of near-IR asteroid spectra. (Rayner et al., 2003)

The near-IR data range reveals diagnostic compositional information because of the presence of features at one and two microns primarily due to the presence of olivine and pyroxene. Other classification systems created using near-IR data include Howell et al. (1994) who created a neural network taxonomy. Gaffey et al. (1993) created an S-complex taxonomy of olivine- and pyroxine-rich asteroids based on near-infrared data. Our goal was to create a taxonomy extending from 
visible to near-infrared wavelengths for the entire suite of asteroid characteristics with a method that can be easily reproduced by future users to classify new data. We also strove to keep the notation consistent with past taxonomies, specifically the Bus taxonomy, to facilitate the transition to this new system. The Bus taxonomy, in turn, strove to keep its notation consistent with the Tholen taxonomy.

The taxonomy we present here is based on Principal Component Analysis. It is comprised of 24 classes compared to 26 in the Bus system with three Bus classes eliminated (Sl, Sk, Ld) and one (Sv) created, as well as the addition of a "w" notation, a mark meant to flag objects having similar spectral features but differing only by having a higher spectral slope. In this paper we present the data involved in the taxonomy and the method and rationale for the class definitions. The taxonomy classes are formally defined by data spanning the wavelength range 0.45 to 2.45 microns as compared with 0.34 to 1.04 microns for Tholen (1984) using eight points, and 0.435 to 0.925 microns for Bus (1999) using 48 points. A method of interpreting near-infrared data from 0.85 to 2.45 microns is also described but for many classes IR-only data do not yield a unique outcome in Principal Component Analysis (PCA) and the data cannot formally be classified. There is also a web application that determines taxonomic types for visible plus near-infrared data or near-infrared-only data based on this extended taxonomy. (http://smass.mit.edu/busdemeoclass.html) 


\section{The Data}

New data presented here are near-infrared spectral measurements from 0.8 to 2.5 microns obtained using SpeX, the low- to medium- resolution near-IR spectrograph and imager (Rayner et al., 2003), on the 3-meter NASA IRTF located on Mauna Kea, Hawaii. As described in DeMeo and Binzel (2008), objects and standard stars were observed near the meridian to minimize their differences in airmass and match their parallactic angle to the fixed N/S alignment of the slit. Frames were taken so that the object was alternated between two different positions (usually noted as the A and B positions) on a $0.8 \times 15$ arcsecond slit aligned north-south. The asteroid spectrum was divided by the spectrum of a solar-type star, giving relative reflectance. Our primary solar analog standard stars were 16 Cyg B and Hyades 64. Additional solar analog stars with comparable spectral characteristics were utilized around the sky. Two to three sets of eight spectra per set were taken for each object, with each with exposures typically being 120 seconds. The total integration time for each of these objects therefore ranged from 30 to 120 minutes. 
Reduction was performed using a combination of routines within the Image Reduction and Analysis Facility (IRAF), provided by the National Optical Astronomy Observatories (NOAO) (Tody, 1993), and Interactive Data Language (IDL). We use a software tool called "autospex" to streamline reduction procedures. Autospex writes macros containing a set of IRAF (or IDL) command files that are then executed by the image processing package. Autospex procedures operate on a single night at a time, with the opportunity for the user to inspect and verify the results at each stage. Briefly, autospex writes macros that: trim the images down to their useful area, create a bad pixel map from flat field images, flat field correct all images, perform the sky subtraction between $\mathrm{AB}$ image pairs, register the spectra in both the wavelength and spatial dimensions, co-add the spectral images for individual objects, extract the 2-D spectra from co-added images, and then apply the final wavelength calibration. Using IDL, an absorption coefficient based on the atmospheric transmission (ATRAN) model by Lord (1992) is determined for each object and star pair that best minimizes atmospheric water absorption effects for that pair. This coefficient correction is most important near 1.4 and 2.0 microns, locations of major absorption bands due to telluric $\mathrm{H}_{2} \mathrm{O}$. The final IDL step averages all the object and standard pairs to create the final reflectance spectrum for each object.

Most (321) visible wavelength spectra (usually 0.4 to 0.9 microns) were taken from the Small Main Belt Asteroid Spectroscopic Survey (SMASS II) data set (Bus and Binzel, 2002a). Our sample was comprised of 371 objects with both visible and nearIR data. For a table of observations and references for all data included in this work as well as the final taxonomic designations for all objects see Appendix A. The spectra are plotted in Appendix D. 


\section{Creating the Taxonomy}

Principal Component Analysis (PCA) is a method of reducing the dimensionality of a data set, involving coordinate transformations to minimize the variance. The first transformation rotates the data to maximize variance along the first axis, known as Principal Component $1\left(\mathrm{PC1}^{\prime}\right)$, the second axis is the second Principal Component $\left(\mathbf{P C 2}^{\prime}\right)$. The first few principal components contain the majority of the information. For a more thorough explanation of PCA and why it is useful for asteroid taxonomy refer to Tholen (1984) and Bus (1999).

\subsection{Data Preparation}

To prepare our data, we created spline fits to our spectra which smoothed the spectra creating a best fit curve. This reduced the risk that noise or missing data points would influence the resulting taxonomy. We sampled the region 0.45 to 2.45 microns and recorded values of the spline fit at increments of 0.05 microns resulting in 41 datapoints.

The splined data were then normalized at 0.55 microns and the slope was removed from the data and recorded. Using our normalized data, we took a linear regression line of each set of data. The slope $(\gamma)$ of the linear regression line is defined by Eq. 1:

$$
\gamma=\frac{\sum_{\mathbf{0}}^{\mathbf{i}}\left(\mathbf{x}_{\mathbf{i}}-\overline{\mathbf{x}}\right)\left(\mathbf{y}_{\mathbf{i}}-\overline{\mathbf{y}}\right)}{\sum_{\mathbf{0}}^{\mathbf{i}}\left(\mathbf{x}_{\mathbf{i}}-\overline{\mathbf{x}}\right)^{2}}
$$

where $\mathrm{x}_{i}$ is each wavelength value, $\mathrm{y}_{i}$ is each fitted reflectance, and $\bar{x}$ and $\bar{y}$ are their mean values. We note the slope is not constrained to pass through 1 at 
0.55 microns. The calculated slope is thus independent of one's choice for the wavelength at which a spectrum is normalized. The equation of the line defining the slope is then translated in the y-direction to pass through 1 at 0.55 microns.

\section{(equation removed)}

Because slope is the most prominent feature of the spectra we remove it from the data by dividing the slope function, before performing principal component analysis thus making PCA more sensitive to other features. We divide all the data points by the fitted slope. The remaining data are a spectrum with an average slope of zero residuals (including absorption features) above and below the horizontal. We now have data with 41 channels normalized to unity at 0.55 microns with the slope removed. Because each spectrum has a value of 1 at $0.55 \mu \mathrm{m}$, that channel provides no new information and so was removed from the data set to make PCA more effective. Therefore we input 40 channels per object into PCA. Using MATLAB, we then performed PCA on the splined files with slopes removed. We chose to use covariance instead of correlation for the PCA implementation as suggested by Bus (1999).

Following the method of Bus (1999), we verify the slope as a constant signal within all data. Figure 1 displays the first principal component (PC1) of PCA before removing slope compared to the slope we remove directly from the splined data. In the figure it is clear that the two are linearly correlated, justifying the value of removing slope and tabulating it as a spectral parameter.

[Fig. 1: PC1 versus Slope] 


\subsection{Notation}

Here we offer a note on our notation: we use the " ' " notation to denote that principal component analysis is performed on data from which the slope has been removed. Thus $\mathrm{PC}^{\prime}$ is the first principal component of asteroid data that has already had its slope removed. To perform PCA the average value for each channel is subtracted from the data set, resulting in a data set with mean for each channel equal to zero. Note that this notation differs from the Bus (Bus, 1999; Bus and Binzel, 2002b) notation in which the first principal component that has already had its slope removed is $\mathrm{PC} 2^{\prime}$. The supplementary material provides a table of the eigenvalues for the first five principal components and the mean value for each channel. To compute the principal components of a data set, the transpose of the eigenvector is multiplied by the transpose of the mean-subtracted data set as described in Eq. 2:

$$
P C_{x}=\left[E_{x}^{T}\right]\left[D^{T}\right]
$$

where $\mathrm{PC}_{x}$ is principal component $\mathrm{x}, \mathrm{E}_{x}$ is eigenvector $\mathrm{x} . \mathrm{D}$ is the column vector containing an individual reflectance spectrum, normalized to unity at $0.55 \mu \mathrm{m}$, from which the mean channel value (see supplementary material) has been subtracted at each wavelength.

\subsection{Choosing the Number of Principal Components}

Bus (Bus, 1999; Bus and Binzel, 2002b) used slope plus two principal components to characterize visible data contained in 48 wavelength channels. Because 40 wavelength channels were put into our PCA, 40 principal components were the output. Since PCA concentrates the most information in the first dimensions, and 
decreases with each successive dimension, only the first few principal components are useful. To decide how many principal components to use in our analysis we look at the variance contained within each.

The first five principal components contain $99.2 \%$ of the variance, which is sufficient to describe these spectra. $\mathrm{PC4}^{\prime}$ and $\mathrm{PC5}^{\prime}$ were found to be useful for classifying the subtly featured X- and C-complex objects. To find the variance contained within the slope we ran PCA with the slope included in the data. Slope accounts for $88.4 \%$ of all the variance within the data. All the other principal components combined account for $11.6 \%$. Thus, Slope plus the first five PC account for $99.9 \%$ of the variance. Table 1 shows the variances accounted for by the slope and each of the first five principal components. (scree plot figure removed)

[Table 1: Variance within Principal Components]

\section{The Taxonomy}

Of the 371 objects in our sample, 321 were previously assigned labels within the Bus taxonomy. We used this set of 321 objects to guide the class boundaries. The following describes the separation of complexes and classes and the resultant flow chart to reproduce these results using any dataset. Our method is similar to that of Bus (Bus, 1999; Bus and Binzel, 2002a,b); we start by defining the end members, and then move to define the core of each complex. The three main complexes are consistent with past taxonomies: the S-complex displays strong absorptions at 1 and $2 \mu \mathrm{m}$, the C-complex shows low to medium slope and either small or no features, and the X-complex has medium to high slope also displays either small or no fea- 
tures. The complexes are meant to group classes that show similar characteristics. The end member classes are more distinct and separate farther from other types among their principal components. For all the new classifications of the 371 objects in our dataset see Appendix B.

\subsection{The Grand Divide}

The most striking feature seen within the principal component space is the large gap in $\mathrm{PC}^{\prime}$ versus $\mathrm{PC} 2{ }^{\prime}$ space seen in Fig. 2. It appears that this clear boundary distinguishes between spectra that have a $2-\mu \mathrm{m}$ absorption band and those that do not. This "grand divide" is well represented by Eq. 3:

$$
P C 1^{\prime}=-3.00 P C 2^{\prime}-0.28 \bigcirc \quad(\text { line } \alpha)
$$

This "grand divide" is a natural boundary revealed by the principal component analysis that relates $\mathbf{P C 1}^{\prime}$ and $\mathbf{P C 2}^{\prime}$. While no other boundary in this taxonomy is as distinct and well-defined, we used this natural divide as a guide for other, more artificially created boundaries. When defining classes to the right of line $\alpha$, we used lines parallel and orthogonal to it to carve out the space. Fig. 2, 3 and 4 plot all objects in $\mathrm{PC}^{\prime}$ and $\mathrm{PC}^{\prime}$ space. Fig. 2 shows all objects. Fig. 3 shows only objects right of line $\alpha$ plus the A- and Sa-types with the boundaries and line labels that carve out this space. Fig. 4 shows objects left of line $\alpha$ except A- and Sa-types. It is clear from Fig. 4 that the C- and X-complexes do not separate clearly in this PC space. For plots showing the placement of objects in this sample with their Bus, Tholen, and Gaffey labels, see the Supplementary Material.

[Fig. 2: Main plot of all objects in $\mathrm{PC}^{\prime} \mathrm{v} \mathrm{PC1}^{\prime}$ Space]

[Fig. 3: Main plot of all "featured" objects in $\mathrm{PC}^{\prime}$ v $\mathrm{PC}^{\prime}$ Space] 
[Fig. 4: Main plot of all "subtly featureled" objects in $\mathrm{PC} 2^{\prime}$ v $\mathrm{PC} 1$ ' Space]

Except for some L-class objects at the top left of Fig. 2, all objects below and to the left of line $\alpha$ have no two-micron absorption feature and include all subtly featured (C- and X-complex) spectra. By "subtly featured" we mean there may or may not be shallow absorption features particularly in the visible wavelength range, however, there are no prominent one or two-micron absorption bands. Objects plotted to the right of and above the line have a two-micron absorption feature. The only classes that cross this gap are the A- and Sa-classes. Interestingly the K-class, long considered as an intermediate between S and C, falls most squarely in the gap.

While there is no predefined key to understanding the significance of each principal component in separating different spectral types, looking at how the gradient of spectra is distributed in Fig. 2 helps us decipher what effect each principal component has. For objects to the right of line $\alpha$, moving parallel to the line in the decreasing $\mathrm{PC1}^{\prime}$ direction corresponds to increasing 1-micron band depth and width. Moving perpendicular to the line in the increasing $\mathrm{PC2}^{\prime}$ direction (to the right) corresponds to increasing depth and width of the 2-micron band. The $\mathrm{C}$ - and $\mathrm{X}$-complexes have subtler features, and thus have lower $\mathbf{P C 2}^{\prime}$ values while S-complex objects have greater values and strongly featured end members such as V-and R-classes plot furthest to the right with the largest $\mathrm{PC}^{\prime}$ values. As $\mathrm{PC}^{\prime}$ values decrease (moving from top to bottom on Fig. 2) the one-micron band becomes broader and in general deeper. The narrow one-micron band V- types plot on the top right with wide Q- and even wider Sa- and A -types toward the bottom left. Types A, Q, and R with deeper bands all plot below the less extreme S-complex transition types, Sa, Sq, and Sr.

The guiding principle for the classification rules of this taxonomy was to define re- 
gions of principal component space that most consistently envelop objects within each of the original Bus (1999) classes. With this principle as a guide, we subjectively define boundaries so that the most similar spectra consistently fall into the same taxonomic classes. As discussed below, the over-riding criterion of similarity of spectral properties in a class, as examined over the full 0.45 - $2.45 \mu \mathrm{m}$ range, led to some objects in the Bus (Bus, 1999; Bus and Binzel, 2002b) classification receiving new class designations here.

To assign classes for the taxonomy we created a flowchart (Appendix B) containing steps to find a the taxonomic class that results in a consistent grouping of objects with similar spectral properties. The labels for each class follow, except where noted, the same label as Bus (Bus, 1999; Bus and Binzel, 2002b). The order of the flow chart is significant because some classes overlap in certain principal components but can be separated in others.

We start by separating the A- and Sa-classes because they cross over the "grand divide" in $\mathrm{PC}^{\prime}$ and $\mathrm{PC} 2^{\prime}$ space. This is step 1 in the flow chart. Refer to Appendix B for the complete chart. Spectrally, the A-class has a deep and extremely broad absorption band with a minimum near $1 \mu \mathrm{m}$ and may or may not have shallow 2$\mu \mathrm{m}$ absorption band; it also tends to be steeply sloped. The Sa-class has the same characteristic 1- $\mu \mathrm{m}$ absorption band as the A-class, but is less red.

The current Sa-class was redefined from the Bus system because the two Sa objects (main belt object 984 Gretia and Mars crosser 5261 Eureka) in this system were both Sr-types in the Bus system. Since these objects prove to be intermediate between S and A we change the classification of these two (Bus) Sr-types to Sa in this taxonomy. Figure 5 shows the spectral progression from $\mathrm{S}$ to $\mathrm{A}$.

[Fig. 5: Plot of S, Sa, and A spectra]

Step two starts by separating all objects by the divide (line $\alpha$ ) in $\mathrm{PC}^{\prime}$ versus 
$\mathrm{PC}^{\prime}$ space, and creates boundaries for objects with a two-micron band. Step three addresses subtly featured objects (the C-and X-complexes) as well as the K-class which has no significant two-micron band and the L-class which may or may not have a two-micron absorption band but nonetheless lies to the left of line $\alpha$.

\subsection{The End Members: $O, Q, R, V$}

We started by looking at the end member classes in PCA space since they separate most clearly, thereby making them the easiest to define. In Fig. 3 one can see lines separating S-complex and end member classes. Equations 3, 4, 5, 6, and 7 bound these classes.

$$
\begin{array}{cc}
P C 1^{\prime}=-3.0 P C 1^{\prime}+1.5 & (\text { line } \delta) \\
P C 1^{\prime}=-3.0 P C 1^{\prime}+1.0 & (\text { line } \gamma) \\
P C 1^{\prime}=\frac{1}{3} P C 1^{\prime}-0.5 & (\text { line } \eta) \\
P C 1^{\prime}=-3.0 P C 1^{\prime}+0.7 & (\text { line } \theta)
\end{array}
$$

The V-class, based on the asteroid 4 Vesta (Tholen 1984), is characterized by its strong and very narrow $1-\mu \mathrm{m}$ absorption band, as well as a strong and wider 2$\mu \mathrm{m}$ absorption feature. Most V-class asteroids that have been discovered are among the Vesta family and are known as Vestoids, although a few other objects have been identified throughout the main belt, such as 1459 Magnya (Lazzaro et al., 2000) and objects from the basaltic asteroid survey by Moskovitz et al. (2008). The R-class, created for its sole member 349 Demboska by Tholen (1984), is similar to the V-class in that it displays deep 1- and 2- $\mu \mathrm{m}$ features, however the onemicron feature is broader than the $\mathrm{V}$-type feature and has a shape more similar to an S-type except with deeper features. The R-class region in 
principal component space is plotted in (Fig. 3). Bus (Bus and Binzel, 2002b)included three other members in the R-class, two of which are included in our sample. These two objects (1904 Massevitch and 5111 Jacliff) were reassigned to the $\mathrm{V}$-class after discovering that in the near-infrared their one-micron bands remain very narrow. Moskovitz et al. (2008) list 5111 Jacliff as an "Rtype interloper" within the Vesta family, but it appears to be an object more confidently linked to Vesta. 1904 Massevitch, however, has a semimajor axis of 2.74 AU. The unusual spectrum and outer belt location for asteroid 1904 has been noted previously (e.g. Burbine and Binzel (2002)). In the sample we present here, asteroids 1904 Massevitch and 1459 Magnya (Lazzaro et al., 2000) are the only two V-types beyond 2.5 AU, a region where $\mathrm{V}$-type asteroids are rare (Binzel et al., 2006, 2007; Moskovitz et al., 2008).

The O-class also has only one member, 3628 Boznemcova, defined by Binzel et al. (1993). Boznemcova is unique with a very rounded and deep, bowl shape absorption feature at 1-micron as well as a significant absorption feature at $2 \mu \mathrm{m}$. (boundary line information removed) Even though the class is separated in the flow chart, more data on R-type and O-type objects may help establish more rigorously their region boundaries. Bus (Bus and Binzel, 2002b) designated three other asteroids as O-type, 4341 Poseiden, 5143 Heracles, and 1997 RT. Only 5143 was included in our sample. Asteroid 5143 is reclassified here as a Q-type because with near-infrared data it is clear the object did not have the distinct "bowl" shape of the one-micron feature of Boznemcova. This adds 5143 Heracles as a Q-type to those known within near-Earth space (e.g Binzel et al. (2004c)).

The Q-class, whose boundaries are labeled in Fig. 3 was first defined by Tholen (1984) for near-Earth asteroid 1862 Apollo. The class is characterized by a deep and distinct $1-\mu \mathrm{m}$ absorption feature with evidence of another feature near $1.3 \mu \mathrm{m}$ as 
well as a $2-\mu \mathrm{m}$ feature with varying depths among objects. The spectral differences between the end member classes V, R, Q, and $\mathrm{O}$ are displayed in Fig. 6 .

\section{(figure removed)}

[Fig. 6: Plot of V, O, Q, R spectra.]

\subsection{The S-Complex: S, Sa, Sq, Sr, Sv}

Just as in the case of the Bus taxonomy, the S-complex was by far the most difficult to subdivide. Most Bus classes within the S-complex seemed to blend together or scatter randomly in all combinations of PCA components. For example, many objects labeled as "Sa" and "Sl" in the Bus (Bus, 1999; Bus and Binzel, 2002b) taxonomy no longer form distinct groups when their spectra are extended into the near-IR. Most original Bus class objects of these types merged into the S-class. Sa objects were most easily distinguishable not by absorption features, but by their greater slope (caused by slope increases in the 1- to 1.5-micron range). Similarly, many Bus S, Sq, and Sk objects become less clearly separated when their spectra extend to the near-infrared. Within PCA space, the Bus S, Sq, and Sk objects were initially impossible to define clearly because the boundaries blur and overlap. Because spectrally the main difference between the classes of the S-complex appears to be the width of the 1-micron absorption band we used the wavelength range 0.8 to 1.35 microns and performed PCA on only S-complex objects to gain insight on their differences.

Once we used this S-class PCA as a guide, it became more clear how to separate classes within $\mathrm{PC}^{\prime}$ and $\mathrm{PC} 2{ }^{\prime}$. We continued to use boundaries parallel and perpendicular to line $\alpha$. Each class has its own region in $\mathrm{PC}^{\prime}$ and $\mathrm{PC}^{\prime}$ space. Fig. 3 shows the S-complex boxes labeled in PCA space. The previously defined equations 3, 5, 6, plus Eqs. 8, 9, and 10 bound the S-complex. 


$$
\begin{array}{rrr}
P C 1^{\prime}= & =3.0 P C 1^{\prime}+0.35 & (\text { line } \beta) \\
P C 1^{\prime}=\frac{1}{3} P C 1^{\prime}-0.10 & & (\text { line } \zeta) \\
P C 1^{\prime}=\frac{1}{3} P C 1^{\prime}+0.55 & & (\text { line } \varepsilon)
\end{array}
$$

Objects that reside just below the S-class in Fig. 3 appear similar to Q-types, but with more shallow absorption bands. These are Sq-types transitioning between S and Q. Sr-types transition between S- and R-classes. One object (5379 Abehiroshi) was a V-type under the Bus (Bus and Binzel, 2002b) system and is now labeled an Sr. While the visible data have a "moderate to very steep UV slope shortward of $0.7 \mu \mathrm{m}$ with a sharp, extremely deep absorption band longward of $0.75 \mu \mathrm{m}$ " (Bus and Binzel, 2002b), it is clear with the inclusion of near-infrared data that the one-micron absorption band is too wide to be a V-type.

Two objects (2965 Surikov and 4451 Grieve) with high $\mathrm{PC1}^{\prime}$ values, are considered spectrally unique from $\mathrm{Sr}$ because they exhibit very narrow 1- $\mu \mathrm{m}$ absorption bands. The objects in this region spectrally appear to be in transition between S- and V-classes. They are not included in the Bus dataset, and Bus and Binzel (2002b) did not report any cases of objects with these characteristics. Because of their intermediate properties between $\mathrm{S}$ and $\mathrm{V}$ that are clearly displayed over the 0.45 - to 2.45 -micron range, we define a new class with the label Sv. Sk objects in the Bus taxonomy are found to become diverse when the spectra extend to near-IR wavelengths. All of these objects fall into other defined categories. Thus the Sk class is excluded from this new system. Fig. 7 displays the spectra of typical S-, Sq-, Sr-, and Sv-class spectra.

[Fig. 7: Plot of S-complex spectra (S, Sq, Sr, Sv).]

The objects in the S-complex had widely varying spectral slopes. To have some taxonomic distinction in spectral characteristics arising from slope, we made an 
arbitrary cutoff at Slope $=0.25$ dividing high slope objects from other objects. These objects are not relabeled in a class of their own. Instead the S, Sq, Sr, and $\mathrm{Sv}$ objects with high slopes receive a notation of $\mathrm{w}$ added to their name as a moniker for what is commonly discussed as an increase in slope arising from space weathering (Clark et al., 2002). [We make no pretense of knowing whether or not their surfaces are actually weathered.] The high slope S objects are labeled Sw, Sqw, Srw and Svw. We extended this flag to the V-types for which there were two objects with slopes greater than 0.25 , which we label as Vw. Sa-types do not receive a w notation because, as an intermediate class between $\mathrm{S}$ and $\mathrm{A}$, they are by definition highly sloped. Fig. 8 displays the differences between low- and high-slope objects, S and Sw.

[Fig. 8: S versus Sw Spectra]

The choice of 0.25 for the "w" notation is arbitrary. When plotting Bus labeled $\mathrm{S}, \mathrm{Sa}$, and $\mathrm{Sl}$ objects, there is a mixing around the 0.23 to 0.27 slope range. The goal was to keep the "w" notation more selective without setting the boundary too high where objects with unusual slope features (such as deeper UV dropoffs) were preferentially selected rather than focusing on the significant slope range between one and two microns for the S-Complex. Figure 9 plots Slope versus $\mathrm{PC1}^{\prime}$, showing the line separating "w" objects from regular objects.

[Fig. 9: Separation between S and Sw in PC space]

\subsection{The End Members: D, K, L, T}

Step three focuses on objects below or to the left of line $\alpha$ (Eq. 3). We again start by removing end members. Bus (Bus and Binzel, 2002b) objects in the D- and T-classes continue to be easily separated by their high slopes and $\mathrm{PC}^{\prime}, \mathrm{PC} 2^{\prime}$, and 
PC3' values. D-types have spectra that are linear with very steep slope (greater than 0.38), and some show slight curvature or a gentle kink around $1.5 \mu \mathrm{m}$. We note that some objects have their classification most strongly driven by their slope. It is possible for an object in the high-sloped A-class to fall very close to the A/D boundary (for example, the A-type 354 Eleonora). For objects near this boundary, a simple inspection for the presence of a 1- $\mu \mathrm{m}$ absorption band eliminates any possible confusion, where a strong 1- $\mu \mathrm{m}$ band is a distinctive feature of all A-types. T-types are linear with moderate to high slope (between $\mathbf{0 . 2 5}$ and $\mathbf{0 . 3 8}$ ) and often gently concaving down. We separate out L objects based on $\mathrm{PC} 2^{\prime}$ versus $\mathrm{PC} 1^{\prime}$. For objects residing in the $\mathrm{L}$ component space it is necessary to check for Xe-type objects. Xe is a class defined in the Bus system that is generally featureless except for a distinct hook at 0.49 microns, a feature that is not recognized within the first five components of PCA. By visually inspecting the spectrum, one can identify a feature at 0.49 and an absence of a slight feature around 1 micron and label the object as an Xe instead of an L. Refer to Fig. 10 of slope versus $\mathrm{PC1} 1^{\prime}$ which shows how D and L are fairly distinct. The K-types can then be distinguished clearly in $\mathrm{PC} 2^{\prime}$ and $\mathrm{PC} 3^{\prime}$ space.

The Bus (Bus and Binzel, 2002b) L- and K-classes were part of the S-class in the Tholen (1984) taxonomy. While the L-class may show one- and two-micron features, it is distinct from the S-class because the steep slope in visible region levels out abruptly around $0.7 \mu \mathrm{m}$, but does not show a distinct absorption band like the $\mathrm{S}$. There is often a gentle concave down curvature in the near-infrared with a maximum around $1.5 \mu \mathrm{m}$, and there may or may not be a 2-micron absorption feature. A typical K-class object displays a wide absorption band centered just longward of 1 $\mu \mathrm{m}$. This feature is unique because the left maximum and the minimum are sharply pointed and the walls of the absorption are linear with very little curvature. Fig. 11 plots typical spectra for the D-, L-, K-, T-, and X-classes. 
We found that all Ld-type objects under the Bus system diverged into the separate L- and D-classes when near-infrared data were added. Thus the Ld-class itself is not necessary for distinguishing over the visible plus near-infrared wavelength range. The Ld-class does not continue into this new taxonomy.

[Fig. 10: D and L in Slope v PC1' space.]

[Fig. 11: Plot of typical D-, L-, K-, T-, and X-class Spectra]

4.5 The $C$ - and X-Complexes: B, C, Cb, Cg, Cgh, Ch; X, Xc, Xe, Xk

We now consider the core $\mathbf{C}$ - and $\mathbf{X}$-complexes. The B-types are easily distinguished by their negative slope as well as negative $\mathrm{PC}^{\prime}$ and $\mathrm{PC}^{\prime}$ values. Their spectra are linear and negatively sloping often with a slight round bump around 0.6 $\mu \mathrm{m}$ preceding a slight feature longward of 1 micron and/or a slightly concave up curvature in the 1 - to $2-\mu \mathrm{m}$ region. The X-class can then be easily identified based on high slope values between 0.2 and 0.38. At this point Xe and Xk objects may be present in X-class PC space. Our PCA is not particularly sensitive to the small $\mathrm{Xk}$ feature, therefore the spectrum must be visually inspected for a slight feature present usually near 0.9 to 1 micron. If the feature is present, the object is designated an Xk. Xc-types have low to medium slope and are slightly curved and concave downward.

Ch objects have a small positive slope that begins around 1.1 microns and slightly pronounced UV dropoff, and a broad, shallow absorption band centered near $0.7 \mu \mathrm{m}$. The Ch objects are well distinguished in $\mathrm{PC}^{\prime}$ and $\mathrm{PC} 4^{\prime}$ space, but a check must be done to distinguish them from the Cgh-type. The Cgh-class is similar to the Ch showing a 0.7-micron feature, but also has a more pronounced UV dropoff like the $\mathrm{Cg}$-type. The $\mathrm{C}$ - and $\mathrm{Cb}$-types separate in $\mathrm{PC1}^{\prime}, \mathrm{PC} 4^{\prime}$, and $\mathrm{PC} 5^{\prime}$. Figures 
12 and 13 show the C-complex plotted in PCA space. C-types are linear with neutral visible slopes and often have a slight rough bump around $0.6 \mu \mathrm{m}$ and low but positive slope after $1.3 \mu \mathrm{m}$. Cb-types are linear with a small positive slope that begins around $1.1 \mu \mathrm{m}$. Cb objects were intermediate objects between the Band C-classes in the Bus system (Bus and Binzel, 2002b). We keep the same notation, however, the near-infrared data shows, that $\mathrm{Cb}$ objects have low to moderate near-infrared slopes, while the visible slopes are low or negative. There is only one object (175 Andromache) in the Cg-class carrying over from the Bus (Bus, 1999; Bus and Binzel, 2002b) taxonomy. The Cg-class is characterized by a pronounced UV dropoff similar to the Cgh, but does not show the 0.7-micron feature that define $\mathrm{Ch}$ and $\mathrm{Cgh}$. The classes $\mathrm{Cg}, \mathrm{Cgh}, \mathrm{Ch}, \mathrm{Xk}, \mathrm{Xc}$, and Xe do not all separate cleanly in component space because their distinguishing features are weak and not well detected by the first five principal components. These

classes often must be distinguished by visually detecting features described by Bus (1999). A summary of these features are described at the end of the flowchart, Appendix B. Fig. 14 shows typical spectra for classes within the C- and $\mathrm{X}$-complexes.

[Fig. 12: C-Complex in $\mathrm{PC}^{\prime} \mathrm{v} \mathrm{PC1}^{\prime}$ space.] [Fig. 13: C-Complex in $\mathrm{PC}^{\prime}$ v $\mathrm{PC}^{\prime}$ space.] [Fig. 14: Typical C- and X-complex spectra]

\subsection{A Near-Infrared-Only Classification Method}

For many objects, data exist in either the visible or near-infrared wavelength ranges but not both. While taxonomies such as the Bus system (Bus, 1999; Bus and Binzel, 2002b) are available for visible data, no system has been widely accepted for assigning classes to data existing only in the near-infrared. We have adapted our present taxonomy to interpret spectral data available only in the near-infrared range. This 
adaptive taxonomy is not meant to determine a definite class, but instead is an intermediate tool to indicate classes. We especially note that several classes in section 4.5 are carried over unchanged from the Bus taxonomy and are based exclusively on features present at visible wavelengths. Assignment to these classes ( Cg, Cgh, $\mathrm{Xc}, \mathrm{Xe}, \mathrm{Xk}$ ) requires visible wavelength data, therefore objects in these classes cannot be recognized by near-infrared-only data.

To study the ability to classify objects having only near-infrared spectral data we took the same 371 objects used in the original taxonomy but included only data longward of 0.85 microns, again splining the data to smooth out noise. Our spline increments remained $0.05 \mu \mathrm{m}$ covering the range of 0.85 to 2.45 microns resulting in 33 datapoints. We chose to normalize to unity at 1.2 microns, the closest splinefit wavelength value to $1.215 \mu \mathrm{m}$ which is the isophotal wavelength for the $J$ band based on the UKIRT filter set (Cohen et al., 1992). Next, we removed the slope from the data. As in the case with visible and near-infrared data we calculated the slope function without constraints, and then translate it in the $y$-direction to a value of unity at 1.2 microns. We then divide each spectrum by the slope function to remove the slope from the data set.

(equation removed)

In Appendix $\mathrm{C}$ we provide a flowchart to define parameters within $\mathbf{P C A}$ ir space using slope and the first five principal components from $\mathbf{P C A}$ ir (see supplementary material for a table of IR eigenvectors and channel means). These principal components are denoted PCir1' (to signify it is the first near-infrared principal component after slope has been removed), PCir2', PCir3', PCir4', and PCir5' . Principal components greater than PCir5' did not seem to contribute significant information distinguishing classes and were disregarded. In this case, we again start by separating end members and other classes with the most extreme $\mathbf{P} \mathbf{C}_{i r}$ values in step 
1. These classes include: A, Sa, V, Sv, O, R, D. Unfortunately the L-type objects may be mixed in with our definition of Sv- and R-types because they do not fully separate in all cases. In step 2 we address the S-complex, separating it into three groups. Because the entire 1-micron absorption band is not sampled some depth versus slope information is lost, making it difficult to distinguish between a steeply sloped spectrum with a shallow 1-micron feature and a spectrum with a lower slope but a deep 1-micron feature. Step three outlines the $\mathrm{C}$ - and X-complexes. The majority of $\mathrm{C}$ - and X-complex objects are defined by visible wavelength features, so as noted above, their relative classes are completely indistinguishable in an infrared-only spectrum. This is apparent in near-infrared principal component space; most $\mathrm{C}$ - and $\mathrm{X}$-complex objects occupy the same region of space in all components. IR-only data therefore do not yield a unique outcome in Principal Component Analysis (PCA) and the data cannot formally be classified, however the possible types within each principal component space are ranked in order of their prevalence within the data set defining this taxonomy. In such cases where a unique class cannot be determined, visual inspection or quantitative comparison of residuals between the input spectrum and the mean spectrum for each class may help reach a subjective conclusion for one or two classes that appear most likely.

\section{Summary of The Taxonomy}

A "key" displaying the average spectrum for each of the 24 class in this taxonomy corresponding to their locations in principal component space is shown in Fig. 15. The subtly featured C- and X-complexes are to the left while classes displaying distinct one and two-micron features are on the right, with the L-, K-, A-, and Saclasses near the center. This figure is useful for comparing classes and recognizing 
the overall connection between them. Table 2 shows the evolution of the classes from the Bus (Bus, 1999; Bus and Binzel, 2002b) taxonomy to this work by noting classes that have changed and classes that also have the additional "w" notation.

We put this taxonomy in the context of past taxonomies by showing the range of Bus (Bus, 1999; Bus and Binzel, 2002b) and Tholen (1984) classes for objects contained within each class in this taxonomy in Table 3 . It is clear that this visible plus near-infrared wavelength taxonomy is consistent with the spectral groupings of these two visible wavelength range classification systems, although there are some class changes for objects because of detail revealed only in the near-infrared wavelengths. In Table 4 we list the classes of featured objects in our system that fall under each of the Gaffey mineralogic classes (Gaffey et al., 1993). Taxonomy PCA is sensitive to spectral features which often, but not always, have mineralogic implications. Thus a direct mapping from PCA space to mineralogy can only be considered as a general trend. For example, in Fig. 2, the trend from A-type (interpreted as olivine-rich) to V-type (pyroxene-rich) goes from lower left to upper right. Examining the placement of Gaffey class S(I) (olivine-rich) through S(VII) (pyroxene-rich) follows this same trend. These objects generally fall in our S- and Sq-classes. A figure of the Gaffey labels plotted in our principal component space is available in the Supplementary Material.

A verbal description of each class is given in Table 5, explaining the key spectral features and attributes of each particular class and listing at most three objects within our sample that are considered prototypical of that class. This table also summarizes why the three Bus classes ( $\mathrm{Ld}, \mathrm{Sl}, \mathrm{Sk})$ were not continued in this taxonomy. A more quantitative summary of the taxonomy is given in the supplementary material where tables are provided with the mean value and standard 
deviation for the slope and the five principal component for each class, as well as the mean values and standard deviation for each wavelength channel for each class. The supplementary material also provides principal component scores for all 371 objects used to create this taxonomy. Appendix B shows the flowchart to apply this taxonomy to new data. As in Bus (1999) it is a binary response decision tree used to locate the position of the object in multidimensional principal component space, which corresponds to the presence or absence of features that characterize each class.

[Fig. 15 Key of the 24 Taxonomic Classes]

[Table 2: The evolution of the classes from the Bus (1999) taxonomy to this work]

[Table 3: Comparison with Bus and Tholen Taxonomies]

[Table 4: Comparison with Gaffey Minerologies]

[Table 5: Description of Taxonomic Classes]

\section{Conclusion}

An extended taxonomy was created using Principal Component Analysis and visible features to characterize visible and near-infrared wavelength spectra. The system, based on the Bus visible taxonomy from Bus (1999); Bus and Binzel (2002b), has 24 classes compared to 26 in the Bus system. The changes in classes are summarized in Table 2. We eliminated three classes: Ld, Sl, and Sk. All the Bus S subclasses (Sa, Sl, Sk, Sq, Sr) had objects that merged back into the S-class, although many Sq objects remained Sq and two Sr objects were relabeled Sa. A new intermediate class, the Sv-class, was created as a link between the S- and V-classes. Highsloped S, Sq, Sr, Sv, V and Q objects were given a w notation to indicate possible weathering. Many of the classes that lie left of line $\alpha$ in $\mathrm{PC}^{\prime}$ versus $\mathrm{PC}^{\prime}$ space 
are either featureless or exhibit only small features at visible wavelengths identified by Bus (1999); Bus and Binzel (2002b). It is still necessary to use these visible features to distinguish the classes because there are no other corresponding features at near-infrared wavelengths. We have also devised a method to categorize data when solely the near-infrared wavelength range is available, however, without visible wavelength information, the near-infrared taxonomy supplement cannot definitively classify many types especially those in the C- and X-complex, as many of those classes are defined only by visible wavelength features. 371 objects were given types based on this new taxonomic system which was created using 6 dimensions including Slope and $\mathrm{PC} 1^{\prime}$ through $\mathrm{PC} 5^{\prime}$ of Principal Component Analysis. Within our sample, several classes remain relatively rare: only 6 objects fall into the A-class; 349 Dembowska and 3628 Boznemcova reside as the only objects in their respective R- and O-classes. Eight Q-class objects are all near-Earth asteroids. We note 1904 Massevitch as an outer mainbelt V-type while 15 other V-type objects have inner main-belt orbits consistent with an association with Vesta.

\section{Acknowledgements}

We are grateful to numerous colleagues and students who have participated in or contributed to the collection or processing of data throughout the course of this project. These people include, but are not limited to, Mirel Birlan, Thomas Burbine, Jim Elliot, Susan Kern, Alison Klesman, Andrew Rivkin, Paul Schechter, Shaye Storm, Cristina Thomas, and Pierre Vernazza. Particular thanks for their advice and insight to Cristina Thomas, Pierre Vernazza, Jessica Sunshine, and Benoit Carry and to Nick Moscovitz for sharing principal component information of his data. We especially thank Maureen Bell and Beth Clark for sharing their unpublished spectra to improve class boundaries. Thanks to the anonymous referees for 
their many constructive improvements. Observations reported here were obtained at the Infrared Telescope Facility, which is operated by the University of Hawaii under Cooperative Agreement NCC 5-538 with the National Aeronautics and Space Administration, Science Mission Directorate, Planetary Astronomy Program. This paper includes data gathered with the 6.5 meter Magellan Telescopes located at Las Campanas Observatory, Chile. Observations in this paper were also obtained at the Kitt Peak National Observatory, National Optical Astronomy Observatory, which is operated by the Association of Universities for Research in Astronomy, Inc. (AURA) under cooperative agreement with the National Science Foundation. F. E. D. acknowledges funding from the Fulbright Program. This material is based upon work supported by the National Science Foundation under Grant 0506716 and NASA under Grant NAG5-12355. Any opinions, findings, and conclusions or recommendations expressed in this material are those of the authors and do not necessarily reflect the views of the National Science Foundation or NASA. Je donne mes excuses sincères pour ne pas avoir réussi à classifier l'asteroïde B612.

\section{References}

R. P. Binzel, S. Xu, S. J. Bus, M. F. Skrutskie, M. R. Meyer, P. Knezek, and E. S. Barker. Discovery of a Main-Belt Asteroid Resembling Ordinary Chondrite Meteorites. Science, 262:1541-1542, December 1993.

R. P. Binzel, A. W. Harris, S. J. Bus, and T. H. Burbine. Spectral Properties of NearEarth Objects: Palomar and IRTF Results for 48 Objects Including Spacecraft Targets (9969) Braille and (10302) 1989 ML. Icarus, 151:139-149, June 2001.

R. P. Binzel, M. Birlan, S. J. Bus, A. W. Harris, A. S. Rivkin, and S. Fornasier. Spectral observations for near-Earth objects including potential target 4660 Nereus : Results from Meudon remote observations at the NASA Infrared Telescope Facility (IRTF). Planetary and Space Science, 52:291-296, March 2004a. 
R. P. Binzel, E. Perozzi, A. S. Rivkin, A. Rossi, A. W. Harris, S. J. Bus, G. B. Valsecchi, and S. M. Slivan. Dynamical and compositional assessment of nearEarth object mission targets. Meteoritics and Planetary Science, 39:351-366, March 2004b.

R. P. Binzel, A. S. Rivkin, J. S. Stuart, A. W. Harris, S. J. Bus, and T. H. Burbine. Observed spectral properties of near-Earth objects: results for population distribution, source regions, and space weathering processes. Icarus, 170:259-294, August 2004c.

R. P. Binzel, G. Masi, and S. Foglia. Prediction and Confirmation of V-type Asteroids Beyond 2.5 AU Based on SDSS Colors. In Bulletin of the American Astronomical Society, volume 38 of Bulletin of the American Astronomical Society, pages 627, September 2006.

R. P. Binzel, G. Masi, S. Foglia, P. Vernazza, T. H. Burbine, C. A. Thomas, F. E. Demeo, D. Nesvorny, M. Birlan, and M. Fulchignoni. Searching for V-type and Q-type Main-Belt Asteroids Based on SDSS Colors. In Lunar and Planetary Institute Conference Abstracts, volume 38 of Lunar and Planetary Inst. Technical Report, pages 1851, March 2007.

T. H. Burbine. Forging Asteroid-Meteorite Relationships Through Reflectance Spectroscopy. PhD thesis, Massachusetts Institute of Technology, 2000.

T. H. Burbine and R. P. Binzel. Small Main-Belt Asteroid Spectroscopic Survey in the Near-Infrared. Icarus, 159:468-499, October 2002.

S. J. Bus. Compositional structure in the asteroid belt: Results of a spectroscopic survey. PhD thesis, Massachusetts Institute of Technology, January 1999.

S. J. Bus and R. P. Binzel. Phase II of the Small Main-Belt Asteroid Spectroscopic Survey, The Observations. Icarus, 158:106-145, July 2002a.

S. J. Bus and R. P. Binzel. Phase II of the Small Main-Belt Asteroid Spectroscopic Survey, A Feature-Based Taxonomy. Icarus, 158:146-177, July 2002b.

C. R. Chapman, T. V. Johnson, and T. B. McCord. A Review of Spectrophotometric 
Studies of Asteroids. In T. Gehrels, editor, IAU Colloq. 12: Physical Studies of Minor Planets, pages 51-65, 1971.

B. E. Clark, B. Hapke, C. Pieters, and D. Britt. Asteroid Space Weathering and Regolith Evolution. Asteroids III, pages 585-599, 2002.

M. Cohen, R. G. Walker, M. J. Barlow, and J. R. Deacon. Spectral irradiance calibration in the infrared. I - Ground-based and IRAS broadband calibrations. Astronomical Journal, 104:1650-1657, October 1992.

F. DeMeo and R. P. Binzel. Comets in the near-Earth object population. Icarus, 194:436-449, April 2008.

M. J. Gaffey, T. H. Burbine, J. L. Piatek, K. L. Reed, D. A. Chaky, J. F. Bell, and R. H. Brown. Mineralogical variations within the S-type asteroid class. Icarus, 106:573-602, December 1993.

E. S. Howell, E. Merenyi, and L. A. Lebofsky. Classification of asteroid spectra using a neural network. Journal of Geophysical Research, 99:10847-10865, May 1994.

D. A. Jackson. Stopping rules in Principal Component Analysis: A comparison of heuristical and statistical approaches. Ecology, 74:2202-2214, 1993.

D. Lazzaro, T. Michtchenko, J. M. Carvano, R. P. Binzel, S. J. Bus, T. H. Burbine, T. Mothé-Diniz, M. Florczak, C. A. Angeli, and A. W. Harris. Discovery of a Basaltic Asteroid in the Outer Main Belt. Science, 288:2033-2035, June 2000.

S. D. Lord. A new software tool for computing earth's atmospheric transmission of near- and far-infrared radiation. NASA Tech. Mem., (103957), 1992.

N. A. Moskovitz, R. Jedicke, E. Gaidos, M. Willman, D. Nesvorny, R. Fevig, and Z. Ivezic. The Distribution of Basaltic Asteroids in the Main Belt. Icarus, 198: 77-90, November 2008.

J. T. Rayner, D. W. Toomey, P. M. Onaka, A. J. Denault, W. E. Stahlberger, W. E. Vacca, M. C. Cushing, and S. Wang. Spex: A medium-resolution 0.8-5.5 micron spectrograph and imager for the nasa infrared telescope facility. Astron. Soc. of 
the Pacific, 115:362-382, 2003.

A. S. Rivkin, R. P. Binzel, and S. J. Bus. Constraining near-Earth object albedos using near-infrared spectroscopy. Icarus, 175:175-180, May 2005.

D. J. Tholen. Asteroid taxonomy from cluster analysis of photometry. PhD thesis, University of Arizona, 1984.

D. Tody. Iraf in the nineties. in astronomical data. In Astronomical Data Analysis Software and Systems II, 1993.

X. H. J. Wood and G. P. Kuiper. Photometric Studies of Asteroids. Astrophysical Journal, 137:1279-1285, May 1963.

S. Xu. CCD Photometry and Spectroscopy of Small Main-Belt Asteroids. PhD thesis, Massachusetts Institute of Technology, 1994.

S. Xu, R. P. Binzel, T. H. Burbine, and S. J. Bus. Small main-belt asteroid spectroscopic survey: Initial results. Icarus, 115:1-35, May 1995.

B. Zellner, D. J. Tholen, and E. F. Tedesco. The eight-color asteroid survey: Results for 589 minor planets. Icarus, 61:335-416, February 1985. 
Table 1

Variance of Slope and Principal Components

\begin{tabular}{ccc}
\hline $\begin{array}{c}\text { Principal } \\
\text { Component }\end{array}$ & $\begin{array}{c}\text { Variance (\%) } \\
\text { (slope excluded) }\end{array}$ & $\begin{array}{c}\text { Variance (\%) } \\
\text { (slope included) }\end{array}$ \\
\hline Slope & - & 88.4 \\
PC1' & 63.1 & 7.3 \\
PC2' & 24.3 & 2.8 \\
PC3' & 8.9 & 1.0 \\
PC4' & 2.2 & 0.3 \\
PC5' & 0.6 & 0.1 \\
PC6' & 0.3 & 0.1 \\
PC7' & 0.2 & - \\
PC8' & 0.1 & - \\
PC9' & 0.1 & - \\
PC10'-PC40' & 0.1 & - \\
\hline Total: & 100.0 & 100.0 \\
\hline
\end{tabular}

\section{Tables}


Table 2

Evolution from the Bus (1999) Taxonomy to This Work

\begin{tabular}{|c|c|c|}
\hline $\begin{array}{r}\text { Bus } \\
\mathrm{A} \\
\mathrm{B} \\
\mathrm{C} \\
\mathrm{Cb} \\
\mathrm{Cg} \\
\mathrm{Cgh} \\
\mathrm{Ch} \\
\mathrm{D} \\
\mathrm{Ld} \\
\mathrm{L} \\
\mathrm{K} \\
\mathrm{O} \\
\mathrm{Q} \\
\mathrm{R} \\
\mathrm{Sq} \\
\mathrm{Sr} \\
\mathrm{Sa} \\
\mathrm{Sl} \\
\mathrm{Sk} \\
\mathrm{S} \\
\mathrm{T} \\
\mathrm{V} \\
\mathrm{X} \\
\mathrm{Xc} \\
\mathrm{Xe} \\
\mathrm{Xk}\end{array}$ & $\begin{array}{l}\vec{\longrightarrow} \\
\Longrightarrow \\
\vec{\longrightarrow} \\
\vec{\longrightarrow} \\
\vec{\longrightarrow}\end{array}$ & $\begin{array}{l}\mathrm{L} \\
\mathrm{K} \\
\mathrm{O} \\
\mathrm{Q} \\
\mathrm{R} \\
\mathrm{Sr}, \mathrm{Srw} \\
\mathrm{Sq}, \mathrm{Sqw} \\
\mathrm{Sa} \\
\\
\mathrm{S}, \mathrm{Sw} \\
\mathrm{Sv}, \mathrm{Svw} \\
\mathrm{T} \\
\mathrm{V}, \mathrm{Vw} \\
\mathrm{X} \\
\mathrm{Xc} \\
\mathrm{Xe} \\
\mathrm{Xk}\end{array}$ \\
\hline $\begin{array}{l}\text { Total: } 26 \\
\text { Eliminated: } \\
\text { Ld, Sk, Sl } \\
\text { w notation } \\
\text { The double at } \\
\text { The single arrow }\end{array}$ & $\begin{array}{l}\text { does } n \\
\text { row is } \\
\text { is usec }\end{array}$ & $\begin{array}{l}24 \\
\text { Created: } \\
\text { Sv } \\
\text { denote a distinct class } \\
\text { sed for unchanged classes. } \\
\text { for classes that are modified. }\end{array}$ \\
\hline
\end{tabular}


Table 3. Comparison with Bus and Tholen Taxonomies

\begin{tabular}{|c|c|c|c|c|c|}
\hline Class & $\begin{array}{l}\text { Classified } \\
\text { This Work }\end{array}$ & $\begin{array}{l}\text { Classified } \\
\text { By Bus }\end{array}$ & $\begin{array}{l}\text { Classified } \\
\text { By Tholen }\end{array}$ & $\begin{array}{l}\text { Distribution by } \\
\text { Bus Class }\end{array}$ & $\begin{array}{l}\text { Distribution by } \\
\text { Tholen Class }\end{array}$ \\
\hline A & 6 & 6 & 6 & $\mathrm{~A}(5) \mathrm{Sl}(1)$ & $\mathrm{A}(5) \mathrm{S}(1)$ \\
\hline B & 4 & 3 & 3 & $\mathrm{~B}(2) \mathrm{C}(1)$ & $\mathrm{B}(1) \mathrm{F}(1) \mathrm{BCF}(1)$ \\
\hline $\mathrm{C}$ & 12 & 12 & 11 & $\mathrm{C}(9) \mathrm{B}(2) \mathrm{Cb}(1)$ & $\mathrm{C}(6) \mathrm{CF}(1) \mathrm{CU}(1) \mathrm{CX}(1) \mathrm{G}(1) \mathrm{FC}(1)$ \\
\hline $\mathrm{Cb}$ & 3 & 3 & 3 & $\mathrm{Cb}(3)$ & $\mathrm{CF}(1) \mathrm{M}(1) \mathrm{XC}:(1)$ \\
\hline $\mathrm{Cg}$ & 1 & 1 & 1 & $\mathrm{Cg}(1)$ & $\mathrm{C}(1)$ \\
\hline Cgh & 10 & 10 & 7 & $\operatorname{Cgh}(5) \operatorname{Cg}(1) \operatorname{Ch}(2) \mathrm{C}(1) \mathrm{Xc}(1)$ & $\mathrm{C}(4) \mathrm{CU}(1) \mathrm{G}(1) \mathrm{E}(1)$ \\
\hline $\mathrm{Ch}$ & 18 & 18 & 18 & $\mathrm{Ch}(18)$ & $\mathrm{C}(10) \mathrm{G}(4) \mathrm{CG}(2) \mathrm{S}(1) \mathrm{X}(1)$ \\
\hline $\mathrm{D}$ & 16 & 12 & 7 & $\mathrm{D}(4) \mathrm{X}(3) \mathrm{T}(3) \mathrm{Ld}(1) \mathrm{L}(1)$ & $\mathrm{D}(4) \mathrm{DU}(1) \mathrm{ST}(1) \mathrm{X}(1)$ \\
\hline $\mathrm{K}$ & 16 & 15 & 12 & $\mathrm{~K}(10) \mathrm{S}(1) \mathrm{L}(1) \operatorname{Xk}(1) \mathrm{Xc}(1) \mathrm{Sq}(1)$ & $\mathrm{S}(10) \mathrm{SU}(1) \mathrm{T}(1)$ \\
\hline $\mathrm{L}$ & 22 & 21 & 10 & $\mathrm{~L}(10) \mathrm{K}(5) \mathrm{Ld}(4) \mathrm{A}(1) \mathrm{S}(1)$ & S(7) STGD (1) TSD(1) I(1) \\
\hline $\mathrm{O}$ & 1 & 1 & 0 & $\mathrm{O}(1)$ & \\
\hline $\mathrm{Q}$ & 8 & 5 & 2 & $\mathrm{Q}(3) \mathrm{O}(1) \mathrm{Sq}(1)$ & $\mathrm{Q}(1) \mathrm{QU}(1)$ \\
\hline $\mathrm{R}$ & 1 & 1 & 1 & $\mathrm{R}(1)$ & $\mathrm{R}(1)$ \\
\hline $\mathrm{S}$ & 144 & 122 & 65 & $\mathrm{~S}(88) \mathrm{Sl}(10) \mathrm{Sa}(8) \mathrm{Sq}(7) \mathrm{A}(4) \operatorname{Sk}(2) \operatorname{Sr}(\mathrm{r}) \mathrm{L}(1)$ & $\mathrm{S}(60) \mathrm{AS}(1) \mathrm{DU}(1) \mathrm{QSV}(1) \mathrm{SR}(1) \mathrm{SU}(1)$ \\
\hline $\mathrm{Sa}$ & 2 & 2 & 0 & $\operatorname{Sr}(2)$ & \\
\hline $\mathrm{Sq}$ & 29 & 24 & 10 & $\mathrm{Sq}(6) \mathrm{Sk}(5) \mathrm{S}(9) \mathrm{Sa}(3) \mathrm{Sr}(1)$ & $\mathrm{S}(9) \mathrm{SQ}(1)$ \\
\hline $\mathrm{Sr}$ & 22 & 19 & 2 & $\mathrm{Sq}(8) \mathrm{S}(8) \mathrm{Sa}(1) \mathrm{Sr}(1) \mathrm{V}(1)$ & $\mathrm{S}(2)$ \\
\hline $\mathrm{Sv}$ & 2 & 0 & 0 & & \\
\hline $\mathrm{T}$ & 4 & 4 & 4 & $\mathrm{~T}(4)$ & $\mathrm{T}(2) \mathrm{D}(1) \operatorname{PCD}(1)$ \\
\hline $\mathrm{V}$ & 17 & 11 & 3 & $\mathrm{~V}(9) \mathrm{R}(2)$ & $\mathrm{V}(3)$ \\
\hline $\mathrm{X}$ & 8 & 7 & 7 & $\mathrm{X}(7)$ & $\mathrm{M}(4) \mathrm{P}(3)$ \\
\hline $\mathrm{Xc}$ & 3 & 3 & 3 & $\mathrm{X}(2) \mathrm{Xk}(1)$ & $\mathrm{M}(2) \mathrm{X}(1)$ \\
\hline $\mathrm{Xe}$ & 7 & 7 & 6 & $\mathrm{Xe}(7)$ & $\mathrm{E}(3) \mathrm{M}(2) \mathrm{MU}(1)$ \\
\hline $\mathrm{Xk}$ & 15 & 14 & 12 & $\mathrm{Xk}(5) \mathrm{X}(5) \mathrm{Xc}(2) \mathrm{K}(1) \mathrm{C}(1)$ & $\mathrm{M}(3) \mathrm{P}(2) \mathrm{X}(2) \mathrm{S}(1) \mathrm{T}(1) \mathrm{C}(1) \mathrm{CX}(2)$ \\
\hline Total & 371 & 321 & 193 & & \\
\hline
\end{tabular}


Table 4

Comparison with Gaffey Mineralogic Classes

\begin{tabular}{lll}
\hline Gaffey Class & $\begin{array}{l}\text { Num Classified } \\
\text { This Work }\end{array}$ & $\begin{array}{l}\text { Distribution by } \\
\text { This Work }\end{array}$ \\
\hline S(I) & 2 & $\mathrm{~A}(1) \mathrm{K}(1)$ \\
S(II) & 2 & $\mathrm{~S}(1) \mathrm{Sq}(1)$ \\
S(II-III) & 1 & $\mathrm{~S}(1) \mathrm{S}$ \\
$\mathrm{S}(\mathrm{III})$ & 3 & $\mathrm{~K}(1) \mathrm{S}(1) \mathrm{Sq}(1)$ \\
S(III-IV) & 1 & $\mathrm{~S}(1) \mathrm{S}(6) \mathrm{Sq}(2)$ \\
$\mathrm{S}(\mathrm{IV})$ & 8 & $\mathrm{~S}(7)$ \\
$\mathrm{S}(\mathrm{V})$ & 7 & $\mathrm{~S}(2)$ \\
S(VI) & 2 & $\mathrm{~S}(1)$ \\
S(VI-VII) & 1 & $\mathrm{~S}(2)$ \\
S(VII) & 2 & \\
\hline
\end{tabular}


Table 5

Spectral Class Descriptions

\begin{tabular}{|c|c|c|}
\hline Class & Description & Prototypes \\
\hline $\mathrm{A}$ & $\begin{array}{l}\text { Deep and extremely broad absorption band with a minimum near } 1 \mu \mathrm{m} \text {, may or may not } \\
\text { have shallow } 2-\mu \mathrm{m} \text { absorption band; very highly sloped. }\end{array}$ & $246,289,863$ \\
\hline B & $\begin{array}{l}\text { Linear, negatively sloping often with a slight round bump around } 0.6 \mu \mathrm{m} \text { and/or a slig } \\
\text { concave up curvature in the } 1 \text { - to } 2-\mu \mathrm{m} \text { region. }\end{array}$ & 2,3200 \\
\hline $\mathrm{C}$ & $\begin{array}{l}\text { Linear, neutral visible slope often a slight rough bump around } 0.6 \mu \mathrm{m} \text { and low but positive } \\
\text { slope after 1.3. May exhibit slight feature longward of } \mathbf{1} \mu \mathbf{m} \text {. }\end{array}$ & $1,10,52$ \\
\hline $\mathrm{Cb}$ & Linear with a small positive slope that begins around $1.1 \mu \mathrm{m}$. & $191,210,785$ \\
\hline $\mathrm{Cg}$ & $\begin{array}{l}\text { Small positive slope that begins around } 1.3 \text { microns and pronounced UV dropoff. (content } \\
\text { removed) }\end{array}$ & 175 \\
\hline $\mathrm{Cgh}$ & $\begin{array}{l}\text { Small positive slope that begins around } 1 \text { micron and pronounced UV dropoff similar to } \mathrm{Cg} \\
\text { (content removed) also includes a broad, shallow absorption band centered near } 0.7 \mu \mathrm{m} \\
\text { similar to Ch. }\end{array}$ & $106,706,776$ \\
\hline $\mathrm{Ch}$ & $\begin{array}{l}\text { Small positive slope that begins around } 1.1 \text { microns and slightly pronounced UV dropoff } \\
\text { (content removed) also includes a broad, shallow absorption band centered near } 0.7 \mu \mathrm{m} \text {. }\end{array}$ & $19,48,49$ \\
\hline $\mathrm{D}$ & Linear with very steep slope, some show slight curvature or gentle kink around $1.5 \mu \mathrm{m}$. & $1143,1542,3248$ \\
\hline K & $\begin{array}{l}\text { Wide absorption band centered just longward of } 1 \mu \mathrm{m} \text {, the left maximum and the minimum } \\
\text { are sharply pointed and the walls of the absorption are linear with very little curvature. }\end{array}$ & $42,579,742$ \\
\hline $\mathrm{L}$ & $\begin{array}{l}\text { Steep slope in visible region leveling out abruptly around } 0.7 \mu \mathrm{m} \text {. There is often a gentle } \\
\text { concave down curvature in the infrared with a maximum around } 1.5 \mu \mathrm{m} \text {. There may or may } \\
\text { not be a 2-micron absorption feature. }\end{array}$ & $236,402,606$ \\
\hline $\mathrm{O}$ & $\begin{array}{l}\text { Very rounded and deep, bowl shape absorption feature at } 1 \text { micron as well as a significant } \\
\text { absorption feature at } 2 \mu \mathrm{m} \text {. }\end{array}$ & 3628 \\
\hline Q & $\begin{array}{l}\text { Distinct } 1-\mu \mathrm{m} \text { absorption feature with evidence of another feature near } 1.3 \mu \mathrm{m} ; \text { a } 2-\mu \mathrm{m} \text { feature } \\
\text { exists with varying depths between objects. }\end{array}$ & $1862,3753,5660$ \\
\hline $\mathrm{R}$ & $\begin{array}{l}\text { Deep } 1 \text { - and } 2-\mu \mathrm{m} \text { features; the one-micron feature is much narrower than a Q-type, but } \\
\text { slightly broader than a V-type. }\end{array}$ & 349 \\
\hline $\mathrm{S}$ & Moderate 1- and 2- $\mu \mathrm{m}$ features. The 2-micron feature may vary in depth between objects. & $5,14,20$ \\
\hline $\mathrm{Sa}$ & $\begin{array}{l}\text { Has a deep and extremely broad absorption band at } 1 \mu \mathrm{m} \text {; has similar features to A-types } \\
\text { but is less red. }\end{array}$ & 984,5261 \\
\hline Sq & $\begin{array}{l}\text { Has a wide } 1-\mu \mathrm{m} \text { absorption band with evidence of a feature near } 1.3 \mu \mathrm{m} \text { like the Q-type, } \\
\text { except the } 1-\mu \mathrm{m} \text { feature is more shallow for the Sq. }\end{array}$ & $3,11,43$ \\
\hline $\mathrm{Sr}$ & $\begin{array}{l}\text { Has a fairly narrow } 1-\mu \mathrm{m} \text { feature similar to but more shallow than an R-type as well as a } \\
2-\mu \mathrm{m} \text { feature. }\end{array}$ & $237,808,1228$ \\
\hline $\mathrm{Sv}$ & $\begin{array}{l}\text { Has a very narrow } 1-\mu \mathrm{m} \text { absorption band similar to but more shallow than a V-type as well } \\
\text { as a } 2-\mu \mathrm{m} \text { feature. }\end{array}$ & 2965,4451 \\
\hline $\mathrm{T}$ & Linear with moderate to high slope and often gently concaving down. & $96,308,773$ \\
\hline V & Very strong and very narrow $1-\mu \mathrm{m}$ absorption and as well as a strong $2-\mu \mathrm{m}$ absorption feature. & $4,1929,2851$ \\
\hline $\mathrm{X}$ & Linear with medium to high slope. & $22,87,153$ \\
\hline $\mathrm{Xc}$ & Low to medium slope and slightly curved and concave downward. & $21,97,739$ \\
\hline $\mathrm{Xe}$ & $\begin{array}{l}\text { Low to medium slope similar to either Xc- or Xk-type, but with an absorption band feature } \\
\text { shortward of } 0.55 \mu \mathrm{m} \text {. }\end{array}$ & $64,77,3103$ \\
\hline $\mathrm{Xk}$ & $\begin{array}{l}\text { Slightly curved and concave downward similar to Xc-type but with a faint to feature between } \\
\mathbf{0 . 8} \text { to } \mathbf{1} \mu \mathbf{m} \text {. }\end{array}$ & $56,110,337$ \\
\hline $\mathrm{Ld}$ & Diverged to L- and D-classes. & $279(\mathrm{D}), 3734(\mathrm{~L})$ \\
\hline Sk & Diverged to the S- and Sq-classes. & $6585(\mathrm{~S}), 3$ (Sq) \\
\hline $\mathrm{Sl}$ & Merged with the S-class. & $17(\mathrm{~S}), 30(\mathrm{~S})$ \\
\hline
\end{tabular}




\section{Figure Captions}

Fig. 1. Results for PC1 versus Slope. PC1 is the first principal component from a data set that did not have the slope removed. It is clear from the plot that PC1 and slope are linearly related and it is thus valid to remove the slope before running PCA to make PCA more sensitive to other features. Our treatment of slope as a tabulated and removed parameter follows the method of Bus (1999).

Fig. 2. Results for $\mathrm{PC}^{\prime}$ versus $\mathrm{PC} 1^{\prime}$. All objects plotted are labeled with their taxonomic classification in this system. Notice the "grand divide" between the Scomplex and the C- and X-complexes. Line $\alpha$ separates objects with and without $2-\mu \mathrm{m}$ absorption bands. The direction orthogonal to line $\alpha$ (increasing $\mathrm{PC} 2{ }^{\prime}$ values) indicates deeper $2-\mu \mathrm{m}$ and narrower $1-\mu \mathrm{m}$ absorption bands. The direction parallel to line $\alpha$ (increasing $\mathbf{P C 1}^{\prime}$ values) indicates wider $1-\mu \mathrm{m}$ absorption bands. The notation "PC1'", "PC22", etc. denotes that these principal components are computed after removal of the slope.

Fig. 3. PC2' versus $\mathbf{P C 1}^{\prime}$ plotted for the S-complex plus A-, Q-, O-, R-, and V-types. Boundaries chosen for each class are shown and lines are labeled with greek letters. As described in the text, all boundaries are perpendicular or parallel to line $\alpha$.

Fig. 4. PC2' versus $\mathrm{PC1}^{\prime}$ plotted for the $\mathrm{C}$ - and $\mathrm{X}$-complexes plus D-, K-, L-, and T-types. This principal component space does not clearly separate the classes.

Fig. 5. Examples of S-, Sa-, and A-classes. There is a clear progression from S-types with a shallow one-micron band and low slope to A-types with a deep one-micron band and high slope. Sa- and A-types show similar 1- $\mu \mathrm{m}$ band absorptions, but Sa-types are much less red than A-types. The class and the asteroid number 
are labeled next to each spectrum.

Fig. 6. Comparison of prototypes for the V-, O-, Q-, and R-classes. Note the $\mathrm{O}$-class has a very wide 1-micron band and the $\mathrm{V}$-class has a very narrow band. The V-types with the deepest 2-micron bands plot farthest from line $\alpha$. For this and all subsequent spectral plots: We present relative reflectances normalized to unity at 0.55 microns; the spectra are offset vertically for clarity of comparison. The class and asteroid number are labeled next to each spectrum.

Fig. 7. Comparison of spectra within the S-complex (S, Sq, Sr, Sv) showing the variation in the one-micron absorption band among these types. Sqtypes have the widest one-micron feature, similar to the Q-class. Sv-types have the narrowest feature, similar to the V-class.

Fig. 8. Illustration of $\mathrm{S}$ and $\mathrm{Sw}$ reflectance spectra. The absorption features for both are very similar. Slope is the most significant distinction between the two, where the " $\mathrm{w}$ " is a notation to denote the slope difference, but does not describe a distinct class. These two spectra are not offset vertically, showing their differences relative to their common normalization at $0.55 \mu \mathrm{m}$.

Fig. 9. Plot of Slope versus PC1' for the S-Complex. All objects in classes S, Sq, $\mathrm{Sr}$ and $\mathrm{Sv}$ with slopes greater than 0.25 have a "w" notation to denote the high slope. This "w" notation not describe a distinct class.

Fig. 10. The distribution of objects left of line $\alpha$ in slope versus $\mathrm{PC}^{\prime}$ space. Here we see a clear separation for D- and T-types because of their high slopes. L-types are distinguished here by their positive $\mathrm{PC}^{\prime}$ values. C-complex objects have the lowest $\mathrm{PC}^{\prime}$ values while $\mathrm{X}$-complex and $\mathrm{K}$-types reside between the L-types and C-complex. 
Fig. 11. Prototype examples of D-, L-, K-, T-, and X-class spectra.

Fig. 12. Close examination of principal component distribution for the C-complex in $\mathrm{PC}^{\prime}$ versus $\mathrm{PC} 1^{\prime}$ space. This figure shows that C-types objects plot to the bottom left, while Xc-, Xe-, and Xk-types plot above the C-class with higher $\mathrm{PC1}^{\prime}$ values. Cgh-types have higher $\mathrm{PC} 5^{\prime}$ values than other objects, and are plotted further right.

Fig. 13. view of the C-complex in $\mathrm{PC}^{\prime}{ }^{\prime}$ versus $\mathrm{PC}^{\prime}{ }^{\prime}$ space. Here we see the C-types plotting in the bottom left of the figure and the Ch-types and Cgh-types having higher $\mathrm{PC} 4^{\prime}$ values plot further to the right.

Fig. 14. Prototype examples for C- and X-complex spectra.

Fig. 15. A "key" showing all 24 taxonomic classes defined over 0.45 $\mathbf{2 . 4 5} \mu \mathbf{m}$. The average spectra are plotted with constant horizontal and vertical scaling and are arranged in a way that approximates the relative position of each class in the primary spectral component space defined by slope, $\mathrm{PC}^{\prime}$, and $\mathrm{PC} 2^{\prime}$ (roughly following Fig. 2). Thus the depth and width of the 2- $\mu \mathrm{m}$ band generally increases lower left to upper right, and the depth and width of the 1- $\mu \mathrm{m}$ band increase moving downward and toward the right. For subtly featured objets slope increases from bottom to top. Due to the spectral complexity of the $\mathrm{C}$ - and $\mathrm{X}$-complexes, the locations of some of these classes do not strictly follow the pattern. The horizontal lines to which each spectrum is referenced has a reflectance value of unity. This figure and description follows the style of Bus and Binzel (2002b, Fig. 15). 


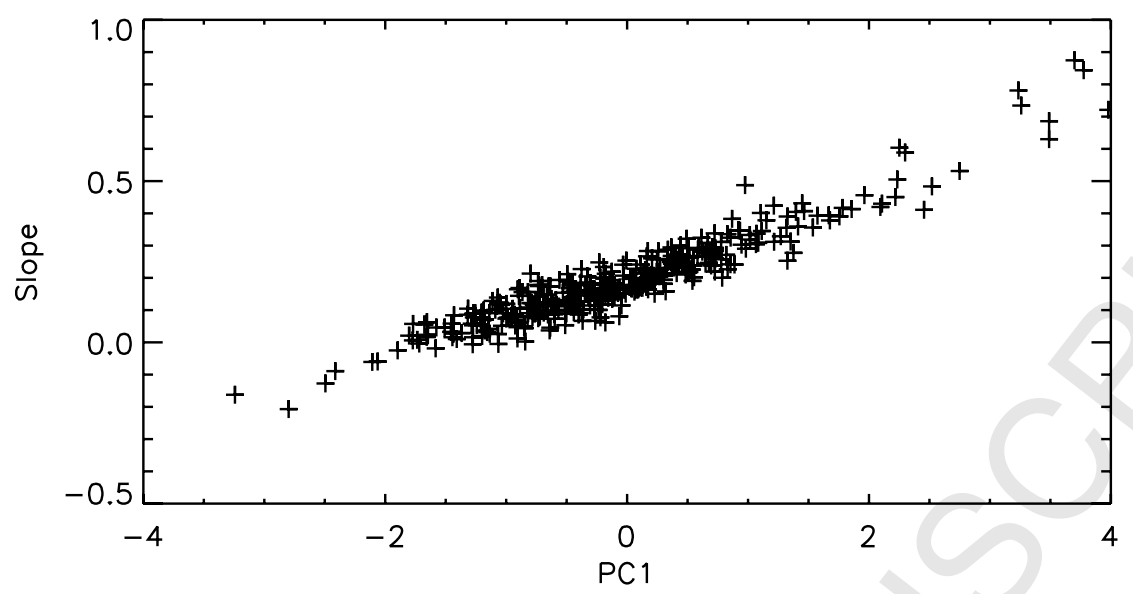

Fig. 1.

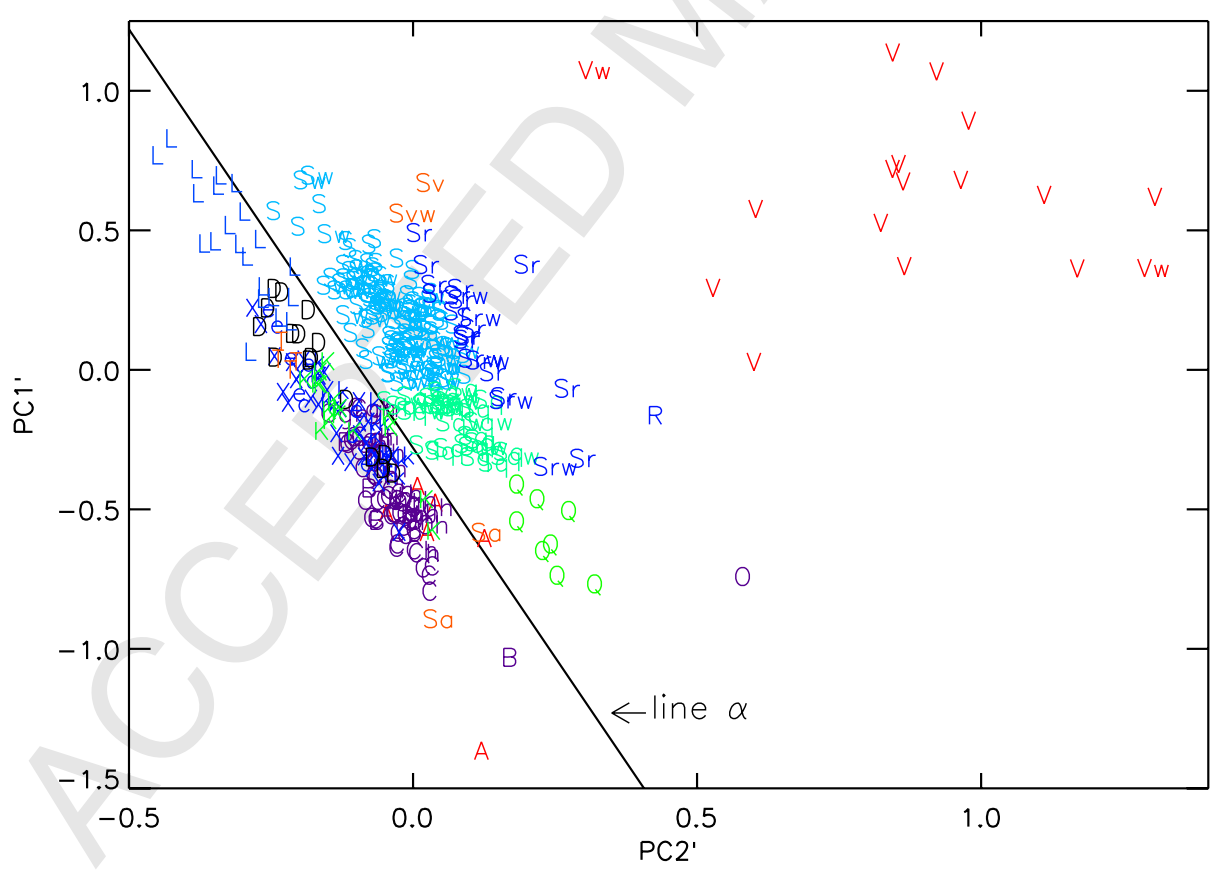

Fig. 2. 


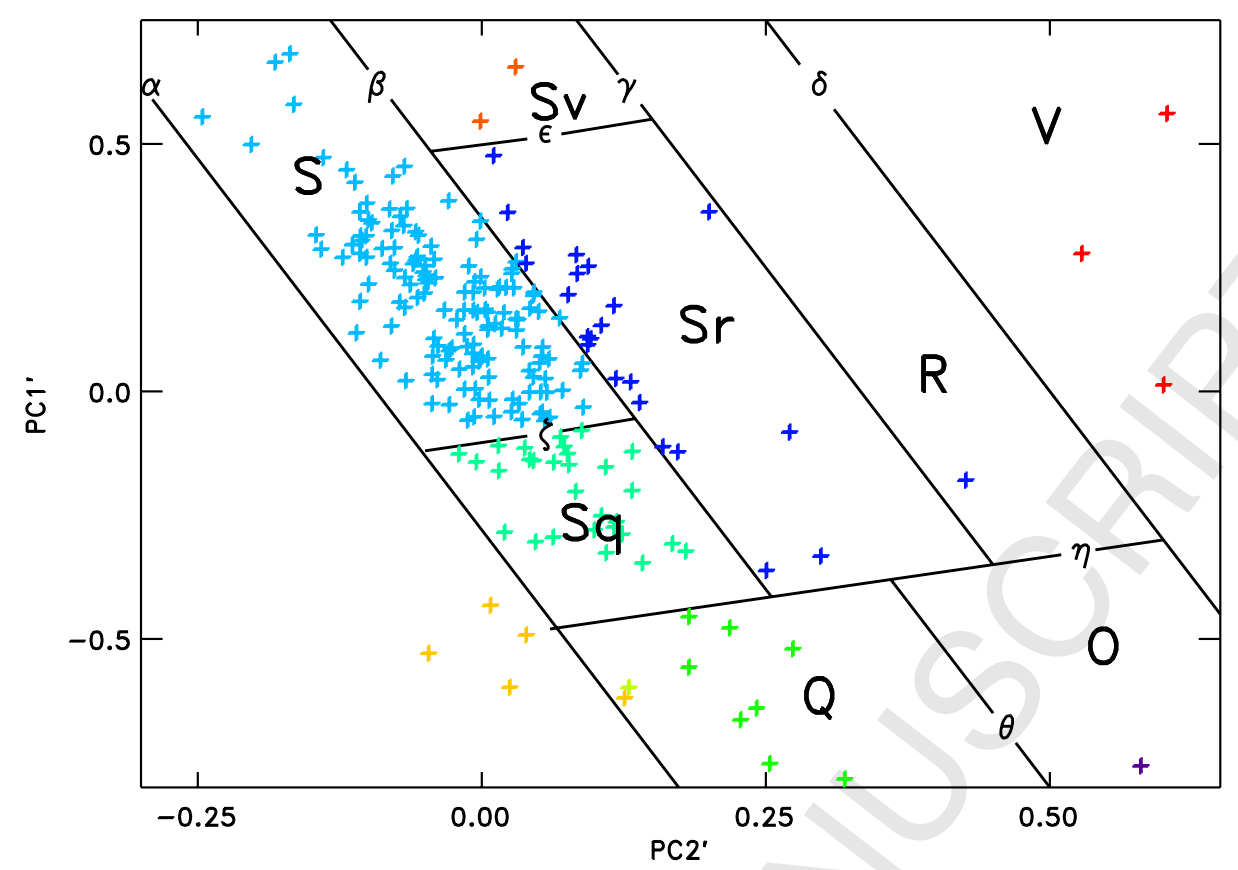

Fig. 3.

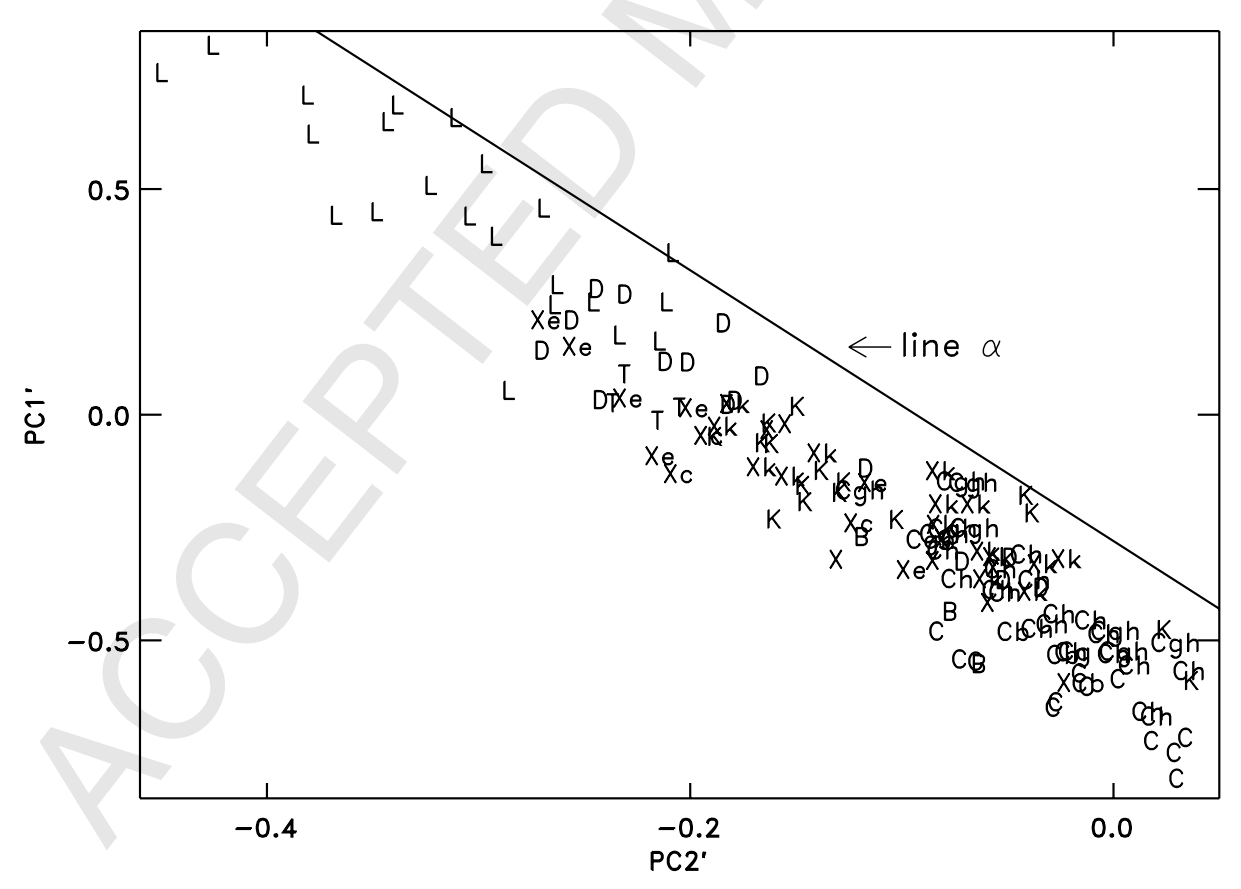

Fig. 4. 


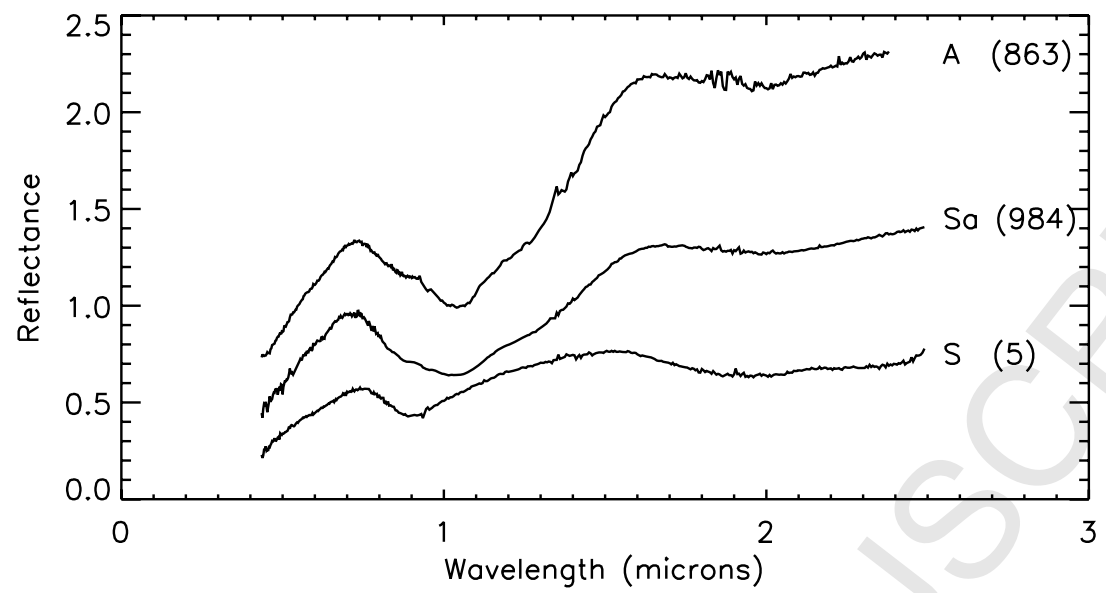

Fig. 5 .

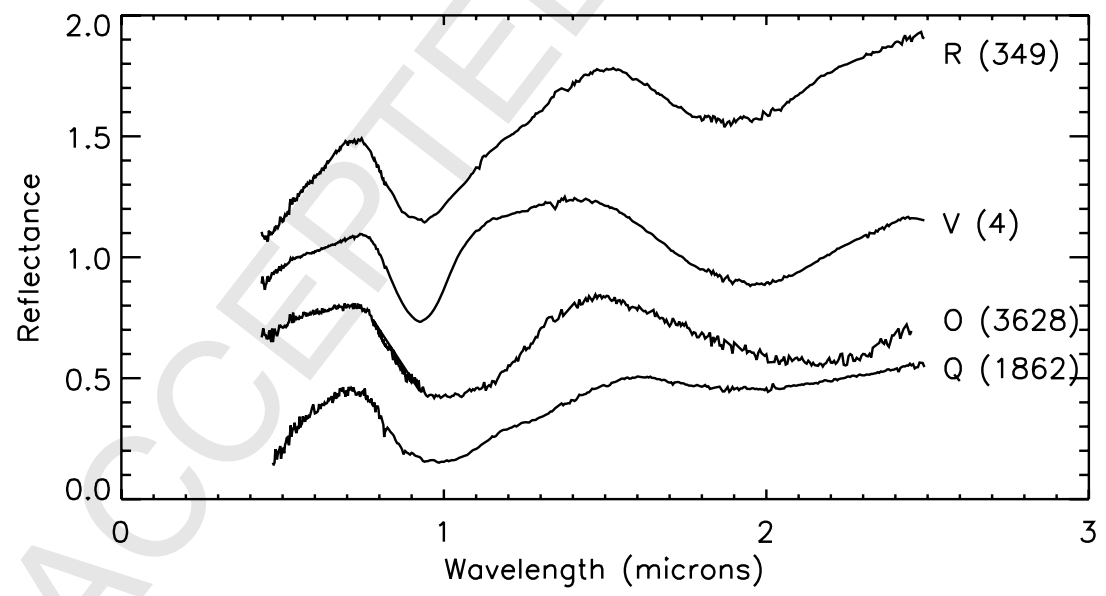

Fig. 6 . 


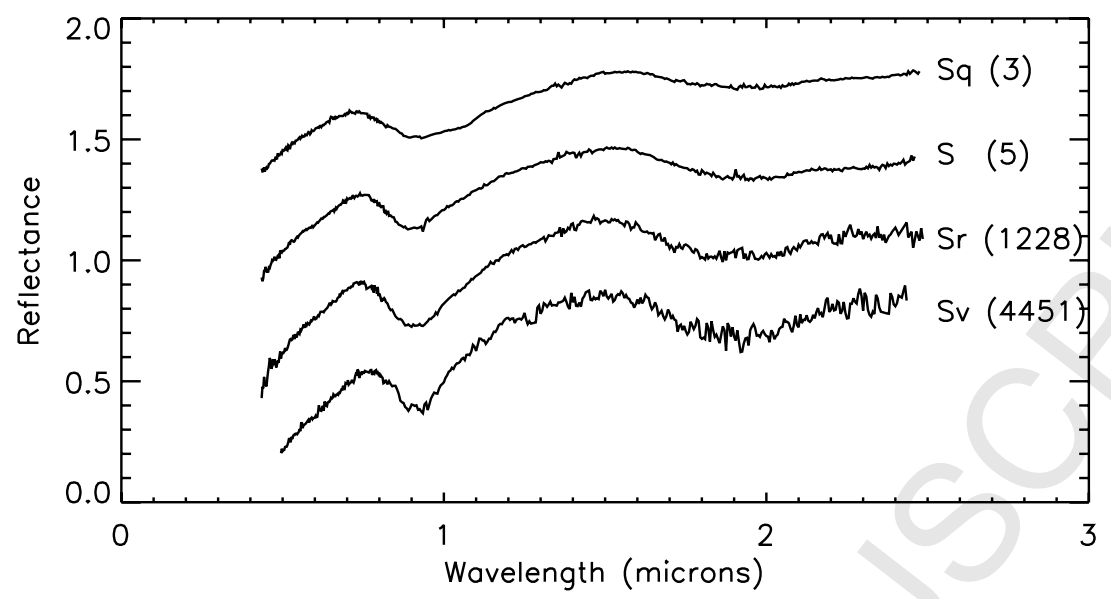

Fig. 7.

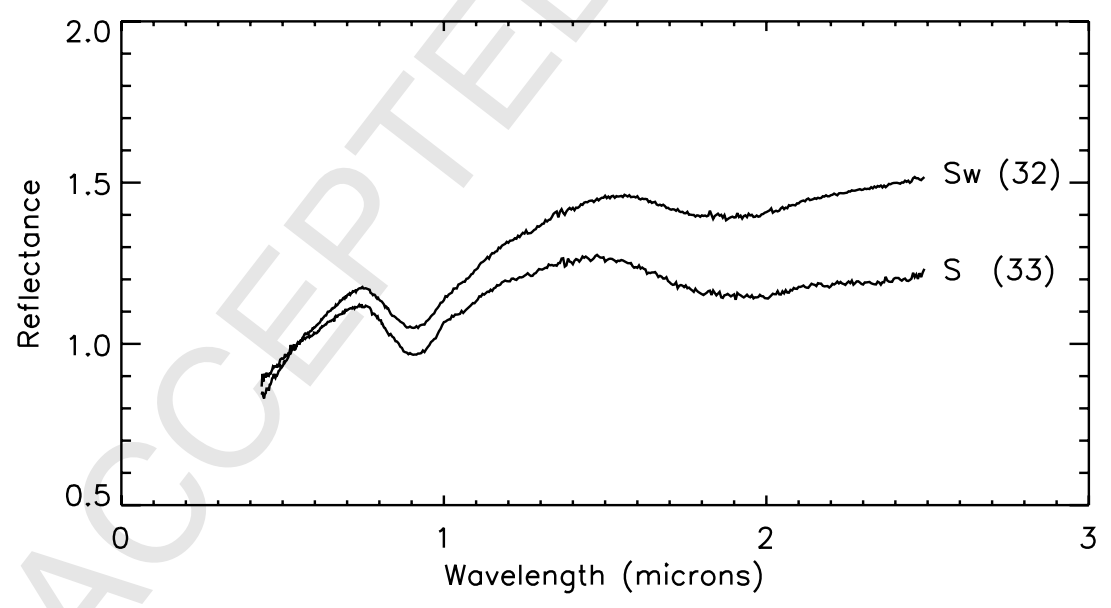

Fig. 8 . 


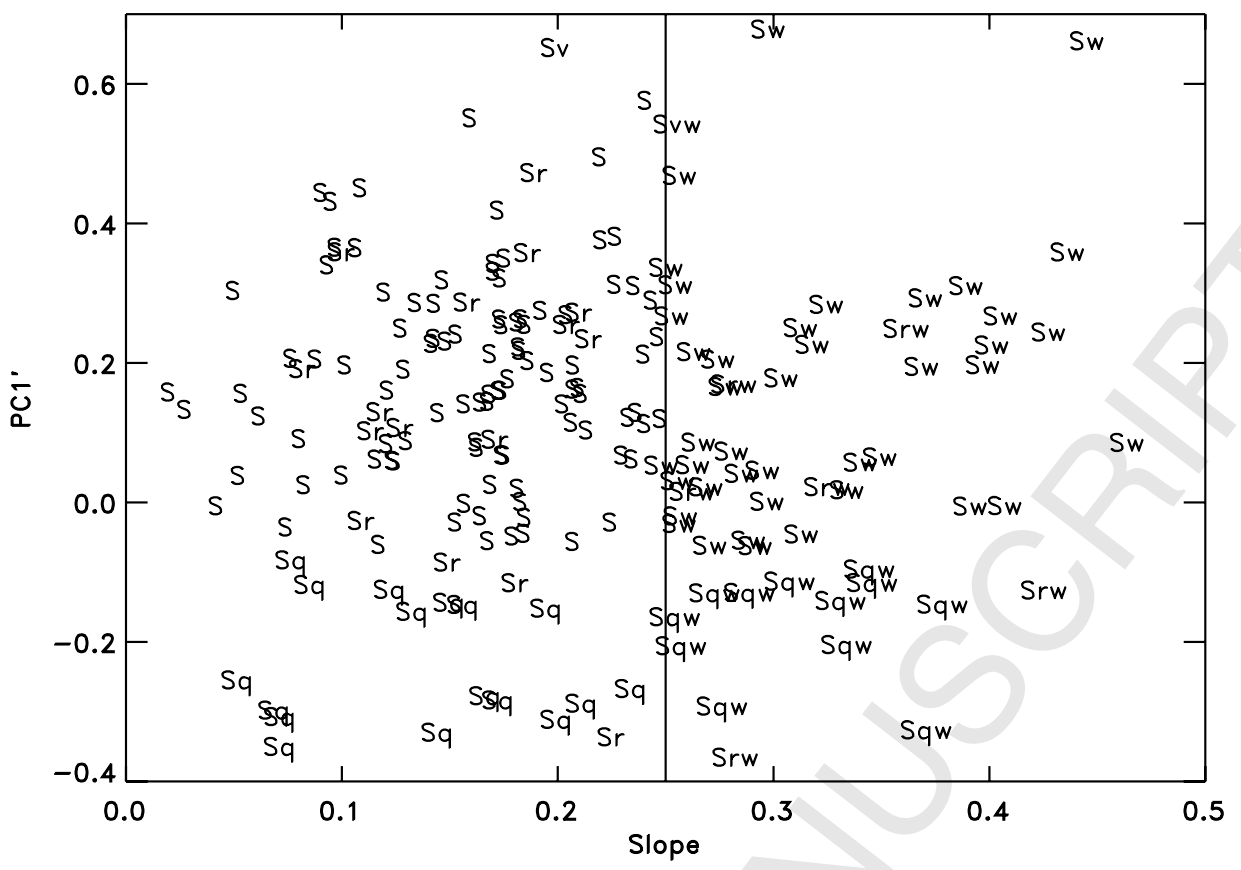

Fig. 9.

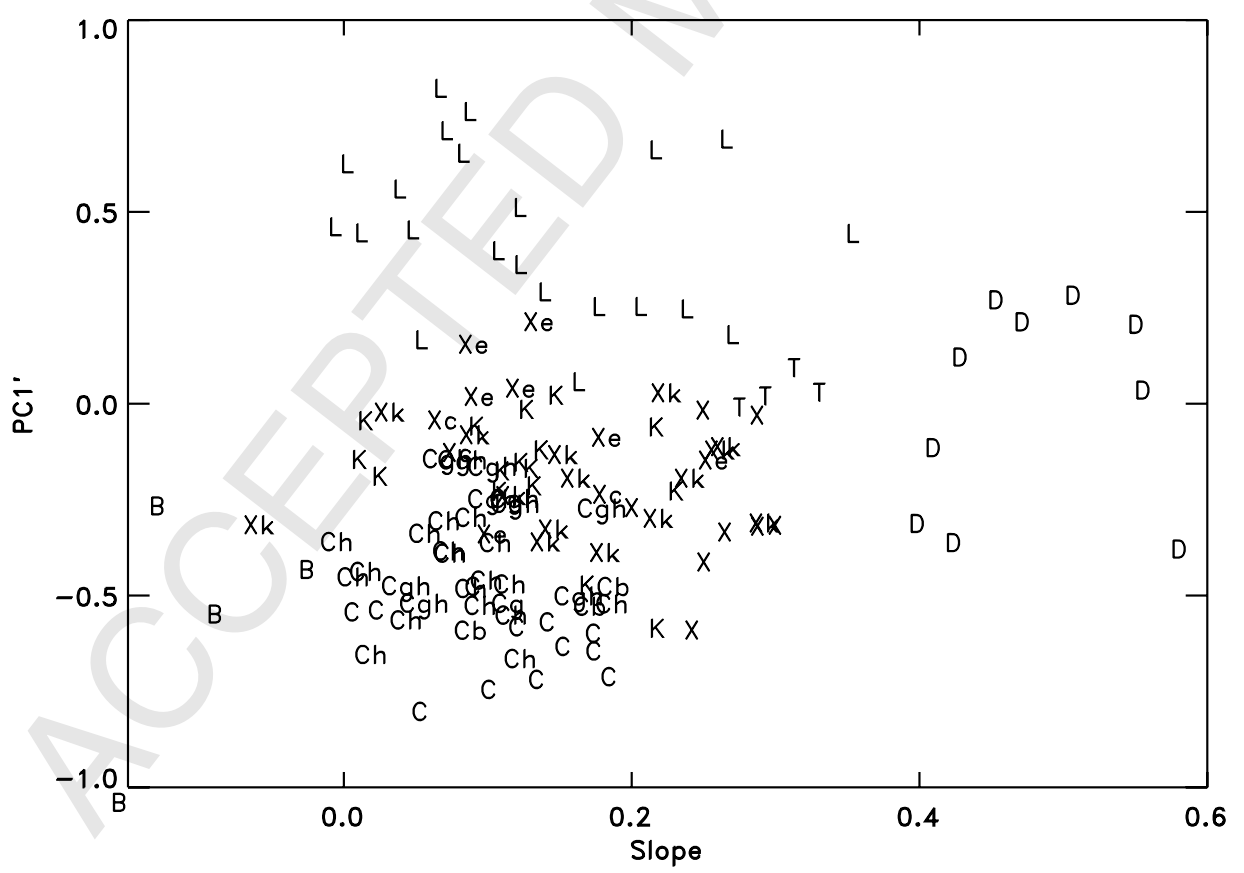

Fig. 10. 


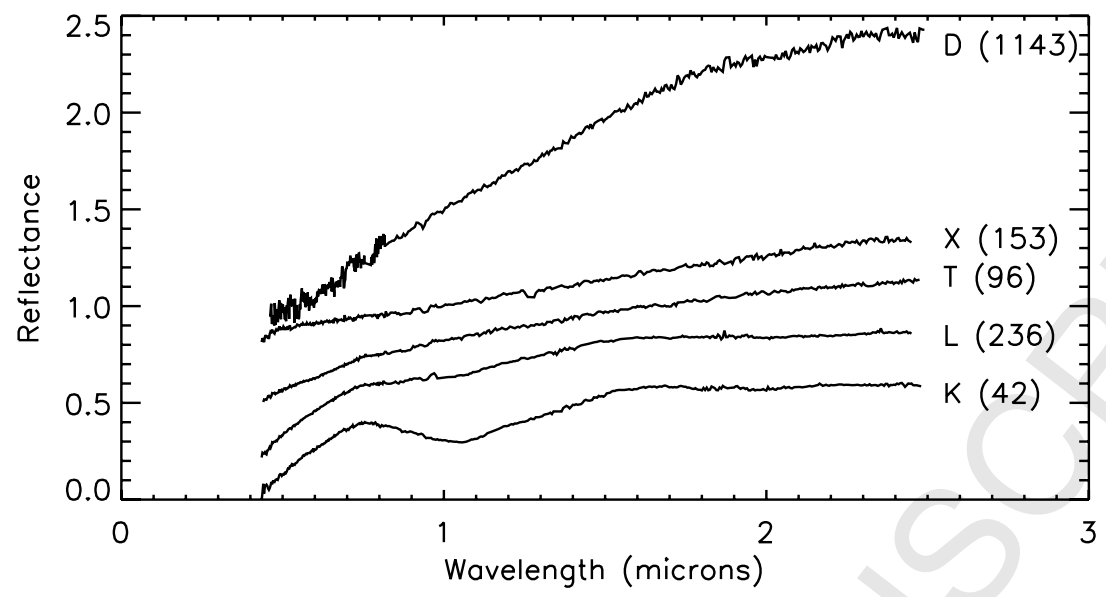

Fig. 11.

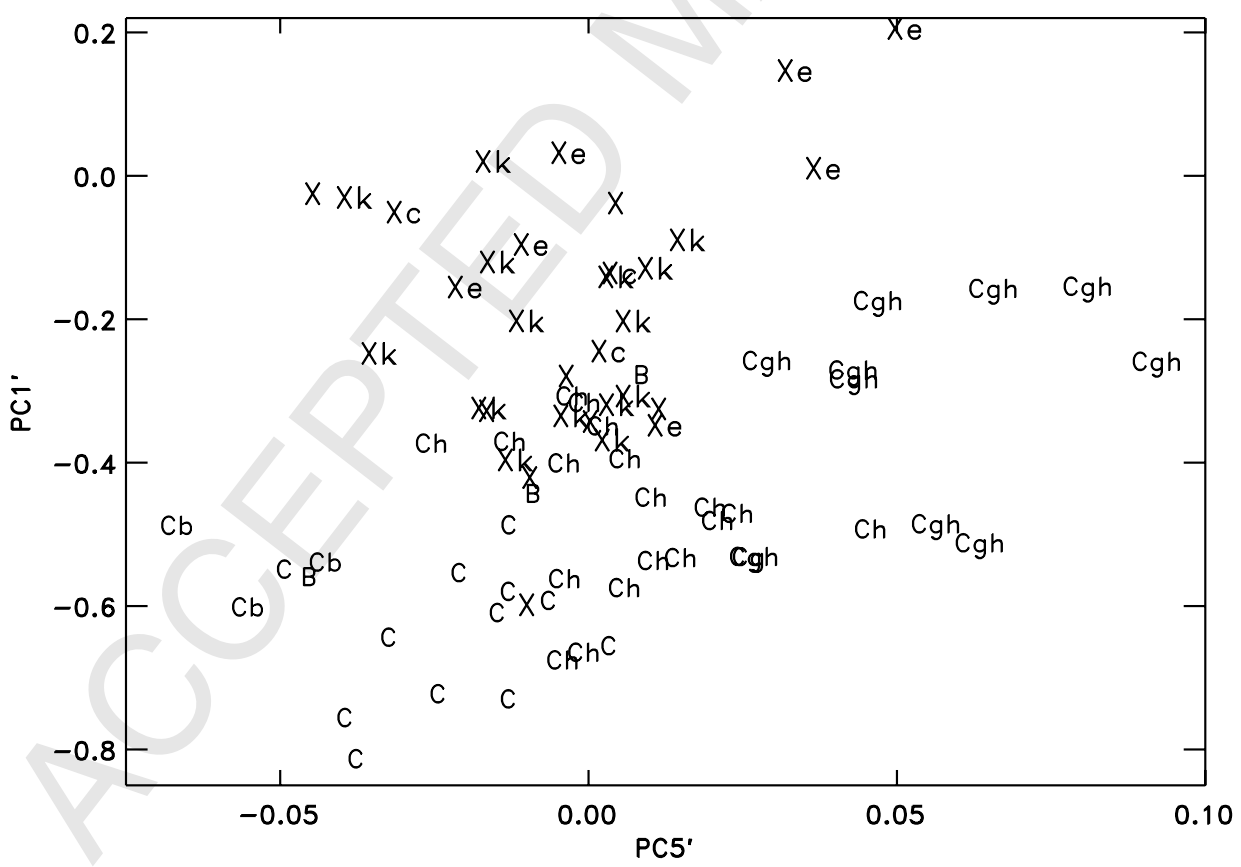

Fig. 12. 


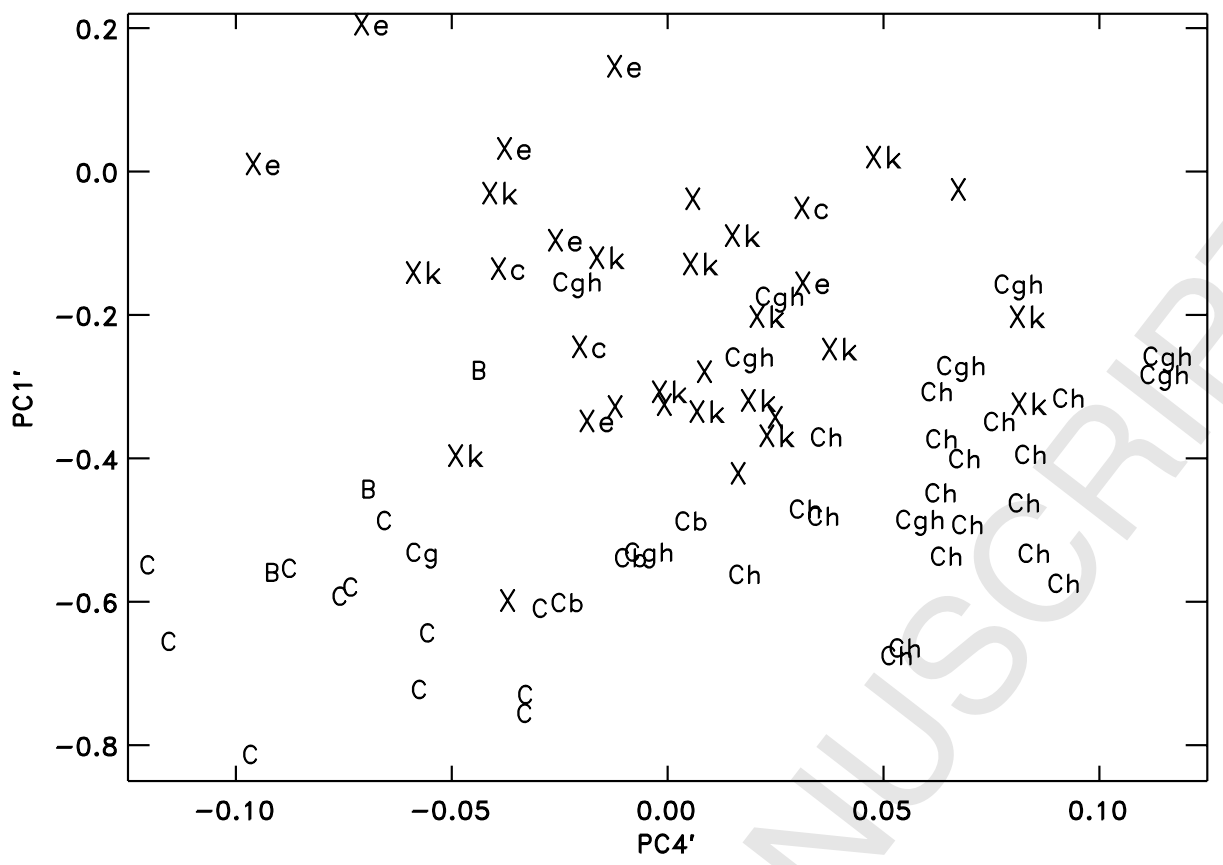

Fig. 13.

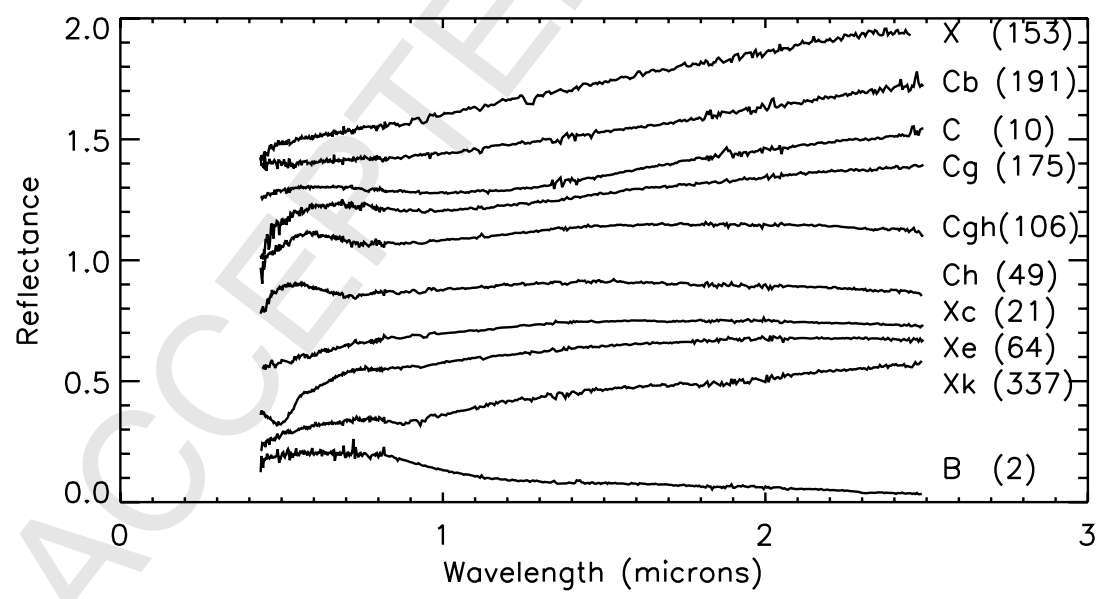

Fig. 14. 


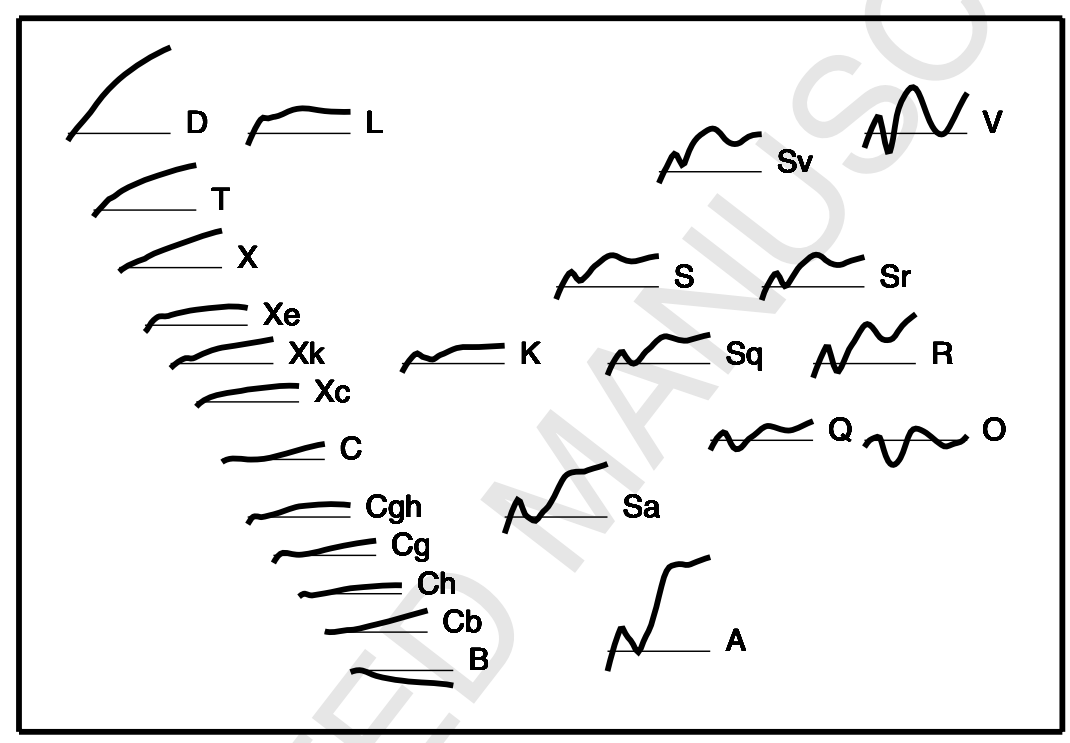

Fig. 15. 
Appendix A. Observations ${ }^{a}$ and Designations

\begin{tabular}{|c|c|c|c|c|c|c|c|c|c|c|c|}
\hline Obj & Name & Tholen & Bus & This Work & Date & Obj & Name & Tholen & Bus & This Work & Date \\
\hline 1 & Ceres & $G$ & $\mathrm{C}$ & $\mathrm{C}$ & 19-May-05 & 52 & Europa & $\mathrm{CF}$ & $\mathrm{C}$ & $\mathrm{C}$ & 28-Jun-06 \\
\hline 2 & Pallas & B & $\mathrm{B}$ & B & 29-Mar-01 & 54 & Alexandra & $\mathrm{C}$ & $\mathrm{C}$ & Cgh & 27-Oct-02 \\
\hline 3 & Juno & $\mathrm{S}$ & Sk & $\mathrm{Sq}$ & 17-Mar-03 & 55 & Pandora & M & $\mathrm{X}$ & $\mathrm{X}$ & 29-Jan-06 \\
\hline 4 & Vesta & V & $\mathrm{V}$ & V & 09-Oct-00 & 56 & Melete & $\mathrm{P}$ & $\mathrm{Xk}$ & $\mathrm{Xk}$ & 22-Sep-04 \\
\hline 5 & Astraea & $\mathrm{S}$ & $\mathrm{S}$ & $\mathrm{S}$ & 20-Feb-04 & 57 & Mnemosyne & $\mathrm{S}$ & $\mathrm{S}$ & $\mathrm{S}$ & 01-Jun-02 \\
\hline 7 & Iris & $\mathrm{S}$ & $\mathrm{S}$ & $\mathrm{S}$ & 20-Feb-04 & 58 & Concordia & $\mathrm{C}$ & $\mathrm{Ch}$ & $\mathrm{Ch}$ & 02-Aug-03 \\
\hline 8 & Flora & $\mathrm{S}$ & & $\mathrm{Sw}$ & $16-$ Sep-02 $b$ & 61 & Danae & $\mathrm{S}$ & $\mathrm{S}$ & $\mathrm{S}$ & 08-Oct-00 \\
\hline 10 & Hygiea & $\mathrm{C}$ & $\mathrm{C}$ & $\mathrm{C}$ & 19-Feb̂-04 & 63 & Ausonia & $\mathrm{S}$ & $\mathrm{Sa}$ & $\mathrm{Sw}$ & 30-Sep-03 \\
\hline 11 & Parthenope & $\mathrm{S}$ & $\mathrm{Sk}$ & $\mathrm{Sq}$ & $13-N o v-05$ & 64 & Angelina & $\mathrm{E}$ & $\mathrm{Xe}$ & $\mathrm{Xe}$ & 30-Jan-01 \\
\hline 13 & Egeria & $\mathrm{G}$ & $\mathrm{Ch}$ & $\mathrm{Ch}$ & 19-Мay-05 & 65 & Cybele & $\mathrm{P}$ & $\mathrm{Xc}$ & $\mathrm{Xk}$ & 30-Sep-03 \\
\hline 14 & Irene & $\mathrm{S}$ & $\mathrm{S}$ & $\mathrm{S}$ & 17-May-01 & 66 & Maja & $\mathrm{C}$ & $\mathrm{Ch}$ & $\mathrm{Ch}$ & 22-Nov-05 \\
\hline 15 & Eunomia & $\mathrm{S}$ & $\mathrm{S}$ & $\mathrm{K}$ & 19-Feb-04 & 67 & Asia & $\mathrm{S}$ & $\mathrm{S}$ & $\mathrm{S}$ & 16-Jun-04 \\
\hline 16 & Psyche & M & $\mathrm{X}$ & $\mathrm{X}$ & 09-Oct-00 & 69 & Hesperia & M & $\mathrm{X}$ & $\mathrm{Xk}$ & 11-Мay-05 \\
\hline 17 & Thetis & $\mathrm{S}$ & $\mathrm{Sl}$ & $\mathrm{S}$ & 15-Aug-01 & 70 & Panopaea & $\mathrm{C}$ & $\mathrm{Ch}$ & Cgh & 29-Sep-02 \\
\hline 18 & Melpomene & $\mathrm{S}$ & $\mathrm{S}$ & $\mathrm{S}$ & 22-Jun-01 & 73 & Klytia & $\mathrm{S}$ & & $\mathrm{S}$ & $16-$ Oct- $03^{b, c}$ \\
\hline 19 & Fortuna & $\mathrm{G}$ & $\mathrm{Ch}$ & $\mathrm{Ch}$ & 29-Jan-06 & 76 & Freia & $\mathrm{P}$ & $\mathrm{X}$ & $\mathrm{X}$ & 05-Sep-05 \\
\hline 20 & Massalia & $\mathrm{S}$ & $\mathrm{S}$ & $\mathrm{S}$ & 22-Jun-01 & 77 & Frigga & MU & $\mathrm{Xe}$ & $\mathrm{Xe}$ & 25-Oct-06 \\
\hline 21 & Lutetia & M & $\mathrm{Xk}$ & $\mathrm{Xc}$ & 22-Sep-04 & 78 & Diana & $\mathrm{C}$ & $\mathrm{Ch}$ & $\mathrm{Ch}$ & 31-Oct-05 \\
\hline 22 & Kalliope & M & $\mathrm{X}$ & $\mathrm{X}$ & $25-$ Oct-06 & 82 & Alkmene & $\mathrm{S}$ & $\mathrm{Sq}$ & $\mathrm{S}$ & 24-Aug-01 \\
\hline 24 & Themis & $\mathrm{C}$ & B & $\mathrm{C}$ & $08-O c t-05$ & 84 & Klio & $\mathrm{G}$ & $\mathrm{Ch}$ & $\mathrm{Ch}$ & 02-Aug-03 \\
\hline 25 & Phocaea & $\mathrm{S}$ & $\mathrm{S}$ & $\mathrm{S}$ & 30-Jan-01 & 85 & Io & $\mathrm{FC}$ & B & $\mathrm{C}$ & $02-A u g-03$ \\
\hline 26 & Proserpina & $\mathrm{S}$ & $\mathrm{S}$ & S & 24-Aug-01 & 87 & Sylvia & $\mathrm{P}$ & $\mathrm{X}$ & $\mathrm{X}$ & 04-Sep-05 \\
\hline 27 & Euterpe & $\mathrm{S}$ & S & $\mathrm{S}$ & 22-Sep-04 & 90 & Antiope & $\mathrm{C}$ & $\mathrm{C}$ & $\mathrm{C}$ & 05-Sep-05 \\
\hline 28 & Bellona & $\mathrm{S}$ & $\mathrm{S}$ & $\mathrm{S}$ & 13-Jan-02 & 92 & Undina & $\mathrm{X}$ & $\mathrm{Xc}$ & $\mathrm{Xk}$ & 08-Oct-00 \\
\hline 29 & Amphitrite & $\mathrm{S}$ & $\mathrm{S}$ & $\mathrm{S}$ & 29-Jan-01 & 93 & Minerva & $\mathrm{CU}$ & $\mathrm{C}$ & $\mathrm{C}$ & 27-Apr-03 \\
\hline 30 & Urania & $\mathrm{S}$ & $\mathrm{Sl}$ & $\mathrm{S}$ & 08-Oct-00 & 96 & Aegle & $\mathrm{T}$ & $\mathrm{T}$ & $\mathrm{T}$ & 28-Jan-06 \\
\hline 32 & Pomona & $\mathrm{S}$ & $\mathrm{S}$ & $\mathrm{Sw}$ & 30-Jan-01 & 97 & Klotho & M & $\mathrm{X}$ & $\mathrm{Xc}$ & 08-Oct-05 \\
\hline 33 & Polyhymnia & $\mathrm{S}$ & $\mathrm{Sq}$ & $\mathrm{S}$ & 06-Mar-02 & 99 & Dike & $\mathrm{C}$ & $\mathrm{Xk}$ & $\mathrm{Xk}$ & 13-Nov-05 \\
\hline 34 & Circe & $\mathrm{C}$ & $\mathrm{Ch}$ & $\mathrm{Ch}$ & 20-Feb-04 & 101 & Helena & $\mathrm{S}$ & $\mathrm{S}$ & $\mathrm{S}$ & 22-Dec-06 \\
\hline 37 & Fides & $\mathrm{S}$ & $\mathrm{S}$ & $\mathrm{S}$ & 15-Aug-01 & 103 & Hera & $\mathrm{S}$ & $\mathrm{S}$ & $\mathrm{S}$ & 14-Aug-01 \\
\hline 38 & Leda & $\mathrm{C}$ & Cgh & Cgh & 05-Jul-03 & 105 & Artemis & $\mathrm{C}$ & $\mathrm{Ch}$ & $\mathrm{Ch}$ & 02-Aug-03 \\
\hline 39 & Laetitia & $\mathrm{S}$ & $\mathrm{S}$ & Sqw & 14-Aug-01 & 106 & Dione & $\mathrm{G}$ & Cgh & Cgh & 02-Aug-03 \\
\hline 40 & Harmonia & $\mathrm{S}$ & $\mathrm{S}$ & $\mathrm{S}$ & 16-Oct-04 & 108 & Hecuba & $\mathrm{S}$ & Sl & Sw & 06-Mar-02 \\
\hline 41 & Daphne & $\mathrm{C}$ & $\mathrm{Ch}$ & $\mathrm{Ch}$ & 15-Sep-04 & 110 & Lydia & M & $\mathrm{X}$ & $\mathrm{Xk}$ & 29-Jan-01 \\
\hline 42 & Isis & $\mathrm{S}$ & $\mathrm{L}$ & K & 21-Jun-01 & 111 & Ate & $\mathrm{C}$ & $\mathrm{Ch}$ & $\mathrm{Ch}$ & 22-Sep-04 \\
\hline 43 & Ariadne & $\mathrm{S}$ & $\mathrm{Sk}$ & $\mathrm{Sq}$ & 22-Nov-05 & 114 & Kassandra & $\mathrm{T}$ & $\mathrm{Xk}$ & K & 28-Jun-06 \\
\hline 48 & Doris & $\mathrm{CG}$ & $\mathrm{Ch}$ & $\mathrm{Ch}$ & 08-Oct-05 & 115 & Thyra & $\mathrm{S}$ & $\mathrm{S}$ & $\mathrm{S}$ & 06-Mar-02 \\
\hline 49 & Pales & $\mathrm{CG}$ & $\mathrm{Ch}$ & $\mathrm{Ch}$ & 02-Aug-03 & 119 & Althaea & $\mathrm{S}$ & $\mathrm{Sl}$ & $\mathrm{S}$ & 21-Jun-01 \\
\hline 50 & Virginia & $\mathrm{X}$ & $\mathrm{Ch}$ & $\mathrm{Ch}$ & 05-Jul-03 & 128 & Nemesis & $\mathrm{C}$ & $\mathrm{C}$ & $\mathrm{C}$ & 02-Aug-03 \\
\hline 51 & Nemausa & $\mathrm{CU}$ & $\mathrm{Ch}$ & Cgh & 15-Jun-04 & 130 & Elektra & $\mathrm{G}$ & $\mathrm{Ch}$ & $\mathrm{Ch}$ & 29-Mar-01 \\
\hline
\end{tabular}


Observations and Designations (cont.)

\begin{tabular}{|c|c|c|c|c|c|c|c|c|c|c|c|}
\hline Obj & Name & Tholen & Bus & This Work & Date & Obj & Name & Tholen & Bus & This Work & Date \\
\hline 131 & Vala & $\mathrm{SU}$ & $\mathrm{Xc}$ & $K$ & $20-J u 1-06$ & 289 & Nenetta & $A$ & $\mathrm{~A}$ & $\mathrm{~A}$ & 04-Sep-00 \\
\hline 132 & Aethra & $\mathrm{M}$ & $\mathrm{Xe}$ & $\mathrm{Xe}$ & 05-Sep-05 & 295 & Theresia & $\mathrm{S}$ & $\mathrm{S}$ & $\mathrm{Sw}$ & 28-Sep-02 \\
\hline 133 & Cyrene & SR & $\mathrm{S}$ & $\mathrm{S}$ & 22-Jun-01 & 308 & Polyxo & $\mathrm{T}$ & $\mathrm{T}$ & $\mathrm{T}$ & 18-Apr-05 \\
\hline 147 & Protogeneia & $\mathrm{C}$ & $\mathrm{C}$ & $\mathrm{C}$ & 02-Aug-03 & 321 & Phaeo & $\mathrm{X}$ & $\mathrm{X}$ & $\mathrm{D}$ & 29-Sep-02 \\
\hline 150 & Nuwa & CX & $\mathrm{Cb}$ & $\mathrm{C}$ & 02-Aug-03 & 337 & Devosa & $\mathrm{X}$ & $\mathrm{X}$ & $\mathrm{Xk}$ & 28-Sep-02 \\
\hline 151 & Abundantia & $\mathrm{S}$ & $\mathrm{Sl}$ & Sw & 13-Nov-05 & 345 & Tercidina & $\mathrm{C}$ & $\mathrm{Ch}$ & $\mathrm{Ch}$ & $08-O c t-05$ \\
\hline 153 & Hilda & $\mathrm{P}$ & $\mathrm{X}$ & $\mathrm{X}$ & 10-May-05 & 346 & Hermentaria & S & $\mathrm{S}$ & $\mathrm{S}$ & 31-May-02 \\
\hline 158 & Koronis & S & S & S & 16-Mar-03 & 349 & Dembowska & $\mathrm{R}$ & $\mathrm{R}$ & $\mathrm{R}$ & 22-Jun-01 \\
\hline 160 & Una & $\mathrm{CX}$ & $\mathrm{C}$ & $\mathrm{Xk}$ & 5-Jul-03 & 352 & Gisela & S & Sl & Sw & 22-Jun-01 \\
\hline 170 & Maria & S & $\mathrm{S}$ & $\mathrm{S}$ & 22-Jun-01 & 354 & Eleonora & $\mathrm{S}$ & $\mathrm{Sl}$ & A & 15-Apr-02 \\
\hline 175 & Andromache & $\mathrm{C}$ & $\mathrm{Cg}$ & $\mathrm{Cg}$ & $13-N o v-05$ & 359 & Georgia & CX & $\mathrm{X}$ & $\mathrm{Xk}$ & 30-Jan-01 \\
\hline 180 & Garumna & $\mathrm{S}$ & $\mathrm{Sq}$ & $\mathrm{Sr}$ & 28-Sep-02 & 371 & Bohemia & QSV & S & $\mathrm{S}$ & 14-Aug-01 \\
\hline 181 & Eucharis & $\mathrm{S}$ & $\mathrm{Xk}$ & $\mathrm{Xk}$ & 30-Sep-03 & 378 & Holmia & $\mathrm{S}$ & $\mathrm{S}$ & $\mathrm{S}$ & 14-Apr-02 \\
\hline 188 & Menippe & $\mathrm{S}$ & $\mathrm{S}$ & $\mathrm{S}$ & 15-Apr-02 & 387 & Aquitania & S & $\mathrm{L}$ & $\mathrm{L}$ & 27-Apr-03 \\
\hline 191 & Kolga & $\mathrm{XC}$ : & $\mathrm{Cb}$ & $\mathrm{Cb}$ & $12-A p r-05$ & 389 & Industria & S & S & S & 24-Aug-01 \\
\hline 192 & Nausikaa & $\mathrm{S}$ & Sl & Sw & $30-A p r-06$ & 402 & Chloe & $\mathrm{S}$ & $\mathrm{K}$ & $\mathrm{L}$ & 19-Feb-01 \\
\hline 199 & Byblis & & $\mathrm{X}$ & $\mathrm{D}$ & 17-Mar-03 & 403 & Cyane & $\mathrm{S}$ & S & S & 27-Apr-03 \\
\hline 201 & Penelope & M & $\mathrm{X}$ & $\mathrm{X}$ & 19-Feb-04 & 433 & Eros & $\mathrm{S}$ & $\mathrm{S}$ & $\mathrm{Sw}$ & 17-Aug-02 \\
\hline 205 & Martha & $\mathrm{C}$ & $\mathrm{Ch}$ & $\mathrm{Ch}$ & 02-Aug-03 & 434 & Hungaria & $\mathrm{E}$ & $\mathrm{Xe}$ & $\mathrm{Xe}$ & 23-Aug-01 \\
\hline 210 & Isabella & $\mathrm{CF}$ & $\mathrm{Cb}$ & $\mathrm{Cb}$ & $13-N o v-05$ & 444 & Gyptis & $\mathrm{C}$ & $\mathrm{C}$ & $\mathrm{C}$ & 15-Aug-01 \\
\hline 214 & Aschera & $\mathrm{E}$ & $\mathrm{Xc}$ & Cgh & 24-Oct-04 & 446 & Aeternitas & A & A & A & 14-Aug-01 \\
\hline 216 & Kleopatra & $\mathrm{M}$ & $\mathrm{Xe}$ & $\mathrm{Xe}$ & 17-Jun-02 & 453 & Tea & S & S & $\mathrm{Sw}$ & 15-Aug-01 \\
\hline 221 & Eos & S & $\mathrm{K}$ & $\mathrm{K}$ & 08-Oct-00 & 456 & Abnoba & & $\mathrm{S}$ & $\mathrm{S}$ & 17-Jun-02 \\
\hline 226 & Weringia & & $\mathrm{S}$ & S & 06-Mar-02 & 460 & Scania & & K & $\mathrm{L}$ & 17-Jun-02 \\
\hline 233 & Asterope & $\mathrm{T}$ & K & $\mathrm{Xk}$ & 29-Sep-02 & 485 & Genua & & $\mathrm{S}$ & $\mathrm{S}$ & 06-Mar-02 \\
\hline 234 & Barbara & $\mathrm{S}$ & $\mathrm{Ld}$ & $\mathrm{L}$ & 22-Dec-06 & 512 & Taurinensis & $\mathrm{S}$ & $\mathrm{S}$ & Sqw & 16-Oct-04 \\
\hline 236 & Honoria & $\mathrm{S}$ & $\mathrm{L}$ & $\mathrm{L}$ & 01-May-06 & 513 & Centesima & $\mathrm{S}$ & $\mathrm{K}$ & $\mathrm{K}$ & 29-Mar-01 \\
\hline 237 & Coelestina & $\mathrm{S}$ & $\bar{S}$ & $\mathrm{Sr}$ & 15-Apr-02 & 532 & Herculina & $\mathrm{S}$ & S & S & 21-Jun-01 \\
\hline 243 & Ida & $\mathrm{S}$ & $\mathrm{S}$ & $\mathrm{Sw}$ & 17-Mar-03 & 570 & Kythera & ST & $\mathrm{T}$ & $\mathrm{D}$ & 20-Feb-04 \\
\hline 244 & Sita & & $\mathrm{Sa}$ & $\mathrm{Sw}$ & 29-Mar-01 & 579 & Sidonia & S & $\bar{K}$ & $\mathrm{~K}$ & 20-Feb-01 \\
\hline 246 & Asporina & $\mathrm{A}$ & $\mathrm{A}$ & A & 09-Mar-05 & 596 & Scheila & $\mathrm{PCD}$ & $\mathrm{T}$ & $\mathrm{T}$ & 01-Jun-02 \\
\hline 250 & Bettina & M & $\mathrm{Xk}$ & $\mathrm{Xk}$ & 16-Oct-03 & 599 & Luisa & $\mathrm{S}$ & K & $\mathrm{L}$ & 19-Feb-01 \\
\hline 258 & Tyche & $\mathrm{S}$ & $\mathrm{S}$ & $\mathrm{S}$ & 24-Aug-01 & 606 & Brangane & TSD & K & $\mathrm{L}$ & 29-Sep-02 \\
\hline 264 & Libussa & S & $\mathrm{S}$ & $\mathrm{S}$ & 19-Мау-05 & 625 & Xenia & & $\mathrm{Sa}$ & $\mathrm{Sw}$ & 20-Feb-01 \\
\hline 266 & Aline & $\mathrm{C}$ & $\mathrm{Ch}$ & $\mathrm{Ch}$ & 05-Sep-05 & 631 & Philippina & S & $\mathrm{S}$ & $\mathrm{S}$ & 29-Sep-02 \\
\hline 267 & Tirza & $\mathrm{DU}$ & D & $\mathrm{D}$ & 02-Aug-03 & 653 & Berenike & $\mathrm{S}$ & $\mathrm{K}$ & $\mathrm{K}$ & 17-Mar-03 \\
\hline 269 & Justitia & & $\mathrm{Ld}$ & $\mathrm{D}$ & 11-May-05 & 661 & Cloelia & $\mathrm{S}$ & $\mathrm{K}$ & $\mathrm{K}$ & 16-Mar-03 \\
\hline 278 & Paulina & & $\mathrm{S}$ & $\mathrm{S}$ & 31-May-02 & 670 & Ottegebe & & $\mathrm{S}$ & $\mathrm{S}$ & 29-Sep-02 \\
\hline 279 & Thule & $\mathrm{D}$ & $\mathrm{X}$ & $\mathrm{D}$ & 08-Jan-05 & 673 & Edda & $\mathrm{S}$ & $\mathrm{S}$ & $\mathrm{L}$ & 21-Jun-01 \\
\hline 288 & Glauke & $\mathrm{S}$ & $\mathrm{S}$ & $\mathrm{S}$ & 29-Sep-02 & 675 & Ludmilla & $\mathrm{S}$ & $\mathrm{S}$ & $\mathrm{Sw}$ & 15-Apr-02 \\
\hline
\end{tabular}


Observations and Designations (cont.)

\begin{tabular}{|c|c|c|c|c|c|c|c|c|c|c|c|}
\hline Obj & Name & Tholen & Bus & This Work & Date & Obj & Name & Tholen & Bus & This Work & Date \\
\hline 679 & $\mathrm{Pax}$ & 1 & $\mathrm{~K}$ & $\mathrm{~L}$ & 19-Feb-01 & 1204 & Renzia & & $S$ & $\mathrm{Sw}$ & 10-Mar-05 \\
\hline 688 & Melanie & & $\mathrm{C}$ & $\mathrm{C}$ & 28-Sep-02 & 1228 & Scabiosa & & $\mathrm{S}$ & $\mathrm{Sr}$ & 16-Mar-03 \\
\hline 699 & Hela & S & $\mathrm{Sq}$ & S & 08-Jan-05 & 1300 & Marcelle & & $\mathrm{Cg}$ & $\mathrm{Cgh}$ & $25-O c t-06$ \\
\hline 706 & Hirundo & & $\mathrm{Cgh}$ & Cgh & 30-Jan-06 & 1329 & Eliane & $\mathrm{S}$ & $\mathrm{S}$ & Sqw & 17-Aug-02 \\
\hline 716 & Berkeley & S & $\mathrm{S}$ & S & 24-Aug-01 & 1332 & Marconia & & $\mathrm{Ld}$ & $\mathrm{L}$ & 10-Jun-05 \\
\hline 719 & Albert & & & $\mathrm{S}$ & 23 -Aug-01 $d$ & 1350 & Rosselia & $\mathrm{S}$ & $\mathrm{Sa}$ & $\mathrm{S}$ & 21-Jun-01 \\
\hline 720 & Bohlinia & S & $\mathrm{Sq}$ & $\mathrm{Sq}$ & 09-Oct-00 & 1374 & Isora & & $\mathrm{Sq}$ & $\mathrm{Sq}$ & 20-Feb-04 \\
\hline 729 & Watsonia & STGD & $\mathrm{L}$ & $\mathrm{L}$ & 14-Aug-01 & 1433 & Geramtina & & $\mathrm{S}$ & $\mathrm{S}$ & 17-Aug-02 \\
\hline 739 & Mandeville & $\mathrm{X}$ & $\mathrm{X}$ & $\mathrm{Xc}$ & 28-Sep-02 & 1459 & Magnya & & & $\mathrm{Vw}$ & 20-Feb-01 $b$ \\
\hline 742 & Edisona & S & K & K & 16-Mar-03 & 1471 & Tornio & & $\mathrm{T}$ & $\mathrm{D}$ & $08-O c t-05$ \\
\hline 773 & Irmintraud & $\mathrm{D}$ & $\mathrm{T}$ & $\mathrm{T}$ & 22-Sep-04 & 1494 & Savo & & $\mathrm{Sa}$ & Sqw & 25-Oct-06 \\
\hline 776 & Berbericia & $\mathrm{C}$ & $\mathrm{Cgh}$ & Cgh & $12-A p r-05$ & 1508 & Kemi & $\mathrm{BCF}$ & $\mathrm{C}$ & B & 19-Feb-04 \\
\hline 782 & Montefiore & $\mathrm{S}$ & Sl & Sw & 22-Jun-01 & 1542 & Schalen & & $\mathrm{D}$ & $\mathrm{D}$ & 18-Apr-05 \\
\hline 785 & Zwetana & $\mathrm{M}$ & $\mathrm{Cb}$ & $\mathrm{Cb}$ & 19-May-05 & 1565 & Lemaitre & & $\mathrm{Sq}$ & S & 03-Mar-05 \\
\hline 789 & Lena & & $\mathrm{X}$ & $\mathrm{Xk}$ & 17-Aug-02 & 1620 & Geographos & $\mathrm{S}$ & $\mathrm{S}^{1}$ & $\mathrm{~S}$ & 29-Jan-01 \\
\hline 793 & Arizona & DU: & $\mathrm{S}$ & $\mathrm{S}$ & 28-Sep-02 & 1640 & Nemo & & $\mathrm{S}$ & $\mathrm{S}$ & 08-Mar-05 \\
\hline 808 & Merxia & & $\mathrm{Sq}$ & $\mathrm{Sr}$ & $14-A u g-01$ & 1642 & Hill & & $\mathrm{S}$ & S & 15-Aug-01 \\
\hline 824 & Anastasia & S & $\mathrm{L}$ & $\mathrm{L}$ & 14-Aug-01 & 1658 & Innes & $\mathrm{AS}$ & & $\mathrm{Sw}$ & 30-Jan-01 $c$ \\
\hline 832 & Karin & & & S & $05-J u l-03^{e}$ & 1659 & Punkaharju & & S & $\mathrm{S}$ & 15-Mar-02 \\
\hline 847 & Agnia & $\mathrm{S}$ & $\mathrm{S}$ & S & 19-Feb-01 & 1660 & Wood & & $\mathrm{S}$ & $\mathrm{S}$ & 08-Mar-05 \\
\hline 863 & Benkoela & $\mathrm{A}$ & $\mathrm{A}$ & $\mathrm{A}$ & 14-Jan-02 & 1662 & Hoffmann & & $\mathrm{Sr}$ & $\mathrm{Sr}$ & 17-Mar-03 \\
\hline 908 & Buda & & $\mathrm{L}$ & $\mathrm{D}$ & 20-Jul-06 & 1667 & Pels & & $\mathrm{Sa}$ & Sw & 28-Oct-02 \\
\hline 913 & Otila & & $\mathrm{Sa}$ & $\mathrm{Sw}$ & 15-Aug-01 & 1685 & Toro & $\mathrm{S}$ & $\mathrm{S}$ & $\mathrm{Sq}$ & 08-May-02 $h$ \\
\hline 925 & Alphonsina & $\mathrm{S}$ & $\mathrm{S}$ & $\mathrm{S}$ & 28-Sep-02 & 1751 & Herget & & $\mathrm{S}$ & $\mathrm{S}$ & 22-Jun-01 \\
\hline 929 & Algunde & & $\mathrm{S}$ & $\mathrm{S}$ & 21-Jun-01 & 1807 & Slovakia & & $\mathrm{S}$ & Sqw & 15 -Sep-04 \\
\hline 944 & Hidalgo & $\mathrm{D}$ & & $\mathrm{D}$ & $22-\operatorname{Sep}-04^{e}$ & 1839 & Ragazza & & $\mathrm{S}$ & $\mathrm{S}$ & 29-Mar-01 \\
\hline 984 & Gretia & & $\mathrm{Sr}$ & $\mathrm{Sa}$ & 29-Sep-02 & 1848 & Delvaux & & $\mathrm{S}$ & $\mathrm{S}$ & 15-Aug-01 \\
\hline 985 & Rosina & & $\mathrm{S}$ & $\mathrm{S}$ & 11-May-05 & 1858 & Lobachevskij & & $\mathrm{L}$ & S & 14-Apr-02 \\
\hline 1011 & Laodamia & S & $\mathrm{Sr}$ & Sw & 12-Jan-02 & 1862 & Apollo & $Q$ & $\mathrm{Q}$ & $\mathrm{Q}$ & $13-N o v-05$ \\
\hline 1020 & Arcadia & & $\mathrm{S}$ & $\mathrm{Sr}$ & 17-Mar-03 & 1864 & Daedalus & SQ & $\mathrm{Sr}$ & $\mathrm{Sq}$ & 29-Mar-01 \\
\hline 1036 & Ganymed & $\mathrm{S}$ & $\mathrm{S}$ & $\mathrm{S}$ & 09-Mar-05 & 1866 & Sisyphus & & & Sw & 21-Nov-06 \\
\hline 1065 & Amundsenia & & $\mathrm{S}$ & $\mathrm{S}$ & 08-Mar-05 & 1903 & Adzhimushkaj & & K & $\mathrm{K}$ & 17-Mar-03 \\
\hline 1094 & Siberia & & $\mathrm{Xk}$ & $\mathrm{Xk}$ & 16-Mar-03 & 1904 & Massevitch & & $\mathrm{R}$ & $\mathrm{V}$ & 04-Sep-00 \\
\hline 1126 & Otero & & $\mathrm{A}$ & $\mathrm{Sw}$ & 20-Feb-01 & 1916 & Boreas & $\mathrm{S}$ & & $\mathrm{Sw}$ & $14-A u g-01^{d}$ \\
\hline 1131 & Porzia & & $\mathrm{S}$ & $\mathrm{S}$ & 11-May-05 & 1929 & Kollaa & & $\mathrm{V}$ & V & $19-F e b-01$ \\
\hline 1139 & Atami & S & $\mathrm{S}$ & $\mathrm{Sw}$ & 05-Sep-05 & 1943 & Anteros & S & & $\mathrm{Sw}$ & 12-Jan-02 $g, h$ \\
\hline 1143 & Odysseus & $\mathrm{D}$ & & $\mathrm{D}$ & 10-Jun-05 ${ }^{b}$ & 1980 & Tezcatlipoca & $\mathrm{SU}$ & $\mathrm{Sl}$ & $\mathrm{Sw}$ & 25-Oct-06 \\
\hline 1147 & Stavropolis & & S & $\mathrm{Sw}$ & 15-Aug-01 & 2035 & Stearns & $\mathrm{E}$ & $\mathrm{Xe}$ & $\mathrm{Xe}$ & 28-Oct-02 \\
\hline 1148 & Rarahu & S & $\mathrm{K}$ & $\mathrm{K}$ & 29-Mar-01 & 2042 & Sitarski & & $\mathrm{Sq}$ & $\mathrm{Sr}$ & 23-Aug-01 \\
\hline 1198 & Atlantis & & & $\mathrm{Sw}$ & $28-O c t-02^{b}$ & 2045 & Peking & & $\mathrm{V}$ & $\mathrm{V}$ & 14-Jan-02 \\
\hline
\end{tabular}


Observations and Designations (cont.)

\begin{tabular}{|c|c|c|c|c|c|c|c|c|c|c|c|}
\hline Obj & Name & Tholen & Bus & This Work & Date & Obj & Name & Tholen & Bus & This Work & Date \\
\hline 2063 & Bacchus & & $\mathrm{Sq}$ & $\mathrm{Sq}$ & 19-May-05 & 3248 & Farinella & & $\mathrm{D}$ & $\mathrm{D}$ & $18-A p r-05$ \\
\hline 2064 & Thomsen & t & $\mathrm{S}^{1}$ & $\mathrm{Sqw}$ & 29-Jun-06 & 3255 & Tholen & & $\mathrm{S}$ & $\mathrm{S}$ & 16-Sep-02 \\
\hline 2074 & Shoemaker & & & $\mathrm{Sw}$ & $30-$ Sep-03 ${ }^{b}$ & 3317 & Paris & & $\mathrm{T}$ & $\mathrm{D}$ & 01-May-06 \\
\hline 2085 & Henan & & $\mathrm{L}$ & $\mathrm{L}$ & 14-Apr-02 & 3363 & Bowen & & $\mathrm{Sq}$ & $\mathrm{Sr}$ & $15-\mathrm{Apr}-02$ \\
\hline 2099 & Opik & S & $\mathrm{Ch}$ & $\mathrm{Ch}$ & $08-O c t-05$ & 3395 & Jitka & & $\mathrm{Sr}$ & $\mathrm{S}$ & 19-Feb-01 \\
\hline 2107 & Ilmari & & $\mathrm{S}$ & $\mathrm{Sw}$ & 29-Jan-06 & 3402 & Wisdom & & & $\mathrm{S}$ & $30-$ Sep-03 ${ }^{e}$ \\
\hline 2157 & Ashbrook & & $\mathrm{S}$ & $\mathrm{S}$ & 16-Mar-03 & 3430 & Bradfield & & $\mathrm{Sq}$ & $\mathrm{S}$ & 17-Jun-02 \\
\hline 2246 & Bowell & $\mathrm{D}$ & $\mathrm{D}$ & $\mathrm{D}$ & $17-A p r-05$ & 3491 & Fridolin & & $\mathrm{Sq}$ & $\mathrm{S}$ & 17-Jun-02 \\
\hline 2335 & James & & & $\mathrm{S}$ & $30-O c t-05$ & 3511 & Tsvetaeva & & $\mathrm{S}^{1}$ & Srw & $15-\mathrm{Apr}-02$ \\
\hline 2353 & Alva & & $\mathrm{S}$ & $\mathrm{S}$ & 31-May-02 & 3628 & Boznemcova & & $\mathrm{O}$ & $\mathrm{O}$ & $30-A p r-06$ \\
\hline 2354 & Lavrov & & $\mathrm{L}$ & $\mathrm{L}$ & 17-Mar-03 & 3635 & Kreutz & & $\mathrm{S}$ & Srw & 12-Nov-05 \\
\hline 2378 & Pannekoek & & Cgh & Cgh & 11-May-05 & 3701 & Purkyne & & $\mathrm{S}$ & $\mathrm{S}$ & 14-Aug-01 \\
\hline 2386 & Nikonov & & $\mathrm{S}$ & S & 17-Jun-02 & 3734 & Waland & & $\mathrm{Ld}$ & $\mathrm{L}$ & 24-Aug-01 \\
\hline 2396 & Kochi & & $\mathrm{Sa}$ & $\mathrm{S}$ & 15-Aug-01 & 3753 & Cruithne & & $\mathrm{Q}$ & $\mathrm{Q}$ & $08-O c t-05$ \\
\hline 2401 & Aehlita & & $\mathrm{S}$ & $\mathrm{S}$ & 17-Aug-02 & 3788 & Steyaert & & $\mathrm{S}$ & S & 17-Mar-03 \\
\hline 2442 & Corbett & & & $\mathrm{V}$ & $15-\mathrm{Sep}-02{ }^{c}$ & 3844 & Lujiaxi & & $\mathrm{L}$ & $\mathrm{L}$ & 27-Apr-03 \\
\hline 2448 & Sholokhov & & $\mathrm{L}$ & $\mathrm{L}$ & 16-Mar-03 & 3858 & Dorchester & & $\mathrm{Sa}$ & Srw & 20-Feb-04 \\
\hline 2501 & Lohja & A & $\mathrm{A}$ & $\mathrm{A}$ & 12-Jan-02 & 3873 & Roddy & & $\mathrm{S}$ & $\mathrm{Sw}$ & 28-Oct-02 \\
\hline 2504 & Gaviola & & $\mathrm{Sq}$ & $\mathrm{Sr}$ & 27-Apr-03 & 3903 & Kliment Ohridski & & $\mathrm{Sq}$ & $\mathrm{S}$ & 16-Sep-02 \\
\hline 2521 & Heidi & & $\mathrm{S}^{1}$ & $\mathrm{~S}$ & 13-Jan-02 & 3908 & Nyx & $\mathrm{V}$ & & $\mathrm{V}$ & 15 -Sep-04 \\
\hline 2566 & Kirghizia & & $\mathrm{V}$ & $\mathrm{V}$ & 16-Sep-02 & 3910 & Liszt & & $\mathrm{S}$ & S & 17-Aug-02 \\
\hline 2579 & Spartacus & & V & V & 10-Oct-00 & 3920 & Aubignan & & $\mathrm{Sa}$ & Sqw & 16-Sep-02 \\
\hline 2715 & Mielikki & & $\mathrm{A}$ & Sw & 15-Aug-01 & 3949 & Mach & & $\mathrm{Sq}$ & $\mathrm{Sq}$ & 24-Aug-01 \\
\hline 2732 & Witt & & $\mathrm{A}$ & $\mathrm{L}$ & 15-Aug-01 & 4038 & Kristina & & & $\mathrm{Vw}$ & $28-O c t-02^{d}$ \\
\hline 2851 & Harbin & & $\mathrm{V}$ & $\mathrm{V}$ & 24-Aug-01 & 4055 & Magellan & V & & $\mathrm{V}$ & $11-A p r-05^{d}$ \\
\hline 2873 & Binzel & & $\mathrm{Sq}$ & $\mathrm{Sq}$ & 13-Jan-02 & 4179 & Toutatis & & Sk & $\mathrm{Sq}$ & 15-Sep-04 \\
\hline 2875 & Lagerkvist & & $\mathrm{S}^{1}$ & $\mathrm{~S}^{1}$ & 16-Mar-02 & 4188 & Kitezh & & $\mathrm{V}$ & V & 14-Aug-01 \\
\hline 2911 & Miahelena & & $\mathrm{S}$ & $\mathrm{Sw}$ & 17-Mar-03 & 4197 & 1982 TA & & $\mathrm{Sq}$ & $\mathrm{Sq}$ & 30-Sep-03 \\
\hline 2912 & Lapalma & & $\mathrm{V}$ & V & 20-Feb-01 & 4352 & Kyoto & & $\mathrm{S}$ & $\mathrm{S}$ & 17-Jun-02 \\
\hline 2957 & Tatsuo & & $\mathrm{K}$ & $\mathrm{K}$ & 16-Mar-03 & 4407 & Taihaku & & $\mathrm{Sa}$ & Sqw & 24-Aug-01 \\
\hline 2965 & Surikov & & & $\mathrm{Sv}$ & 10-May-0 ${ }^{b}$ & 4417 & Lecar & & 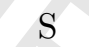 & $\mathrm{Sw}$ & 24-Aug-01 \\
\hline 2977 & Chivilikhin & & S & $\mathrm{S}$ & 28-Sep-02 & 4451 & Grieve & & & Svw & 14-Jan-02 ${ }^{d}$ \\
\hline 3028 & Zangguoxi & & $\mathrm{K}$ & $\mathrm{K}$ & 16-Sep-02 & 4558 & Janesick & & $\mathrm{S}$ & $\mathrm{Sr}$ & 15-Jun-04 \\
\hline 3102 & Krok & $\mathrm{S}$ & & Sqw & $09-O c t-00^{d}$ & 4570 & Runcorn & & $\mathrm{Sa}$ & $\mathrm{Sw}$ & 21-Jun-01 \\
\hline 3103 & Eger & & $\mathrm{Xe}$ & $\mathrm{Xe}$ & 21-Jun-01 ${ }^{i}$ & 4688 & $1980 \mathrm{WF}$ & $\mathrm{QU}$ & & $\mathrm{Q}$ & 29-Jan-01 ${ }^{d}$ \\
\hline 3122 & Florence & & $\mathrm{S}$ & Sqw & 26-Jan-04 & 4713 & Steel & & $\mathrm{A}$ & $\mathrm{Sw}$ & 14-Apr-02 \\
\hline 3155 & Lee & & V & V & 22-Jun-01 & 4737 & Kiladze & & $\mathrm{L}$ & $\mathrm{L}$ & 17-Jun-02 \\
\hline 3198 & Wallonia & & $\mathrm{S}$ & Sqw & 10-May-05 & 4995 & Griffin & & $\mathrm{S}$ & S & 28-Oct-02 \\
\hline 3199 & Nefertiti & $\mathrm{S}$ & $\mathrm{Sq}$ & K & 03-Mar-05 & 5013 & Suzhousanzhong & & $\mathrm{Sl}$ & $\mathrm{Sw}$ & 14-Jan-02 \\
\hline 3200 & Phaethon & $\mathrm{F}$ & $\mathrm{B}$ & B & 10-Dec-04 & 5111 & Jacliff & & $\mathrm{R}$ & V & 05-Sep-05 \\
\hline
\end{tabular}


Observations and Designations (cont.)

\begin{tabular}{|c|c|c|c|c|c|c|c|c|c|c|c|}
\hline Obj & Name & Tholen & Bus & This Work & Date & Obj & Name & Tholen & Bus & This Work & Date \\
\hline 5143 & Heracles & & $\mathrm{O}$ & Q & 25-Oct-06 & 19356 & 1997 GH3 & & S & $\mathrm{Sq}$ & 30-Jan-01 \\
\hline 5230 & Asahina & & S & S & 5-Sep-05 & 20786 & 2000 RG62 & & & $\mathrm{Sq}$ & 1-Sep-03 ${ }^{d}$ \\
\hline 5261 & Eureka & 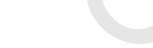 & $\mathrm{Sr}$ & $\mathrm{Sa}$ & 19-Мay-05 & 20790 & $2000 \mathrm{SE} 45$ & & & $\mathrm{~S}$ & 29-Jan-01 ${ }^{d}$ \\
\hline 5379 & Abehiroshi & & $\mathrm{V}$ & $\mathrm{Sr}$ & 3-Jun-06 & 22771 & 1999 CU3 & & & S & $16-O c t-03^{d}$ \\
\hline 5401 & Minamioda & & $\mathrm{S}$ & Sw & 16-Mar-03 & 24475 & $2000 \mathrm{VN} 2$ & & & $\mathrm{Sw}$ & 29-Mar-01 $d$ \\
\hline 5407 & $1992 \mathrm{AX}$ & & $\mathrm{Sk}$ & $\mathrm{S}$ & 13-Jan-02 & 25330 & 1999 KV4 & & & $\mathrm{Xk}$ & $27-O c t-02^{d}$ \\
\hline 5587 & $1990 \mathrm{SB}$ & & $\mathrm{Sq}$ & $\mathrm{Sr}$ & 28-Mar-01 & 35107 & $1991 \mathrm{VH}$ & & Sk & $\mathrm{Sq}$ & 27-Dec-02 \\
\hline 5604 & $1992 \mathrm{FE}$ & & & $\mathrm{V}$ & 29-Mar-01 ${ }^{f}$ & 36284 & 2000 DM8 & & & $K$ & $16-$ Mar-02 ${ }^{d}$ \\
\hline 5641 & McCleese & & $\mathrm{A}$ & Sw & $12-A p r-05$ & 53435 & 1999 VM40 & & & Srw & $25-O c t-06^{g}$ \\
\hline 5660 & $1974 \mathrm{MA}$ & & Q & Q & 22-Aug-93 & 54690 & $2001 \mathrm{~EB}$ & & & S & 28-Mar-01 $d$ \\
\hline 5685 & Sanenobufukui & & S & S & 29-Mar-01 & 66146 & 1998 TU3 & & & $\mathrm{Q}$ & $1-$ Sep-03 ${ }^{e}$ \\
\hline 5817 & Robertfrazer & & S & $\mathrm{Sr}$ & 22-Sep-04 & 86450 & 2000 CK33 & & & $\mathrm{L}$ & 29-Jan-01 ${ }^{d}$ \\
\hline 5840 & Raybrown & & $\mathrm{Ld}$ & $\mathrm{L}$ & 24-Aug-01 & 86819 & 2000 GK137 & & & $\mathrm{Sq}$ & $9-$ Oct-00 ${ }^{d}$ \\
\hline 6047 & 1991 TB1 & & $\mathrm{S}$ & S & 8-Oct-05 & 89355 & 2001 VS78 & & & Sr & 16-Mar-02 \\
\hline 6239 & Minos & & & Sqw & 26-Jan-04 ${ }^{e}$ & 98943 & $2001 \mathrm{CC} 21$ & & & Sw & $24-O c t-04 f$ \\
\hline 6386 & Keithnoll & & S & $\mathrm{S}$ & 3-Mar-05 & 99907 & $1989 \mathrm{VA}$ & & $\mathrm{Sq}$ & $\mathrm{Sr}$ & 27-Oct-02 \\
\hline 6411 & Tamaga & & & B & 20 -Feb-04 ${ }^{e}$ & 137062 & $1998 \mathrm{WM}$ & & $\mathrm{Sq}$ & $\mathrm{Sr}$ & 27-Oct-02 \\
\hline 6455 & $1992 \mathrm{HE}$ & & S & Srw & 28-Oct-02 & 138258 & 2000 GD2 & & & $\mathrm{Sq}$ & $16-O c t-03^{d}$ \\
\hline 6585 & O'Keefe & & Sk & $\mathrm{S}$ & 25 -Oct-06 & 162058 & 1997 AE12 & & & Q & 15-Mar-02 \\
\hline 7341 & $1991 \mathrm{VK}$ & & $\mathrm{Sq}$ & Q & 16-Mar-02 & 162781 & 2000 XL44 & & & $\mathrm{S}$ & 29-Jan-01 ${ }^{d}$ \\
\hline 7763 & Crabeels & & $\mathrm{L}$ & $\mathrm{L}$ & 1-Jun-02 & 2000PG3 & & & & $\mathrm{D}$ & 4-Sep-00 $d$ \\
\hline 8334 & $1984 \mathrm{CF}$ & & S & $\bar{S}$ & 17-Mar-03 & 2001TX16 & & & & $\mathrm{X}$ & 15 -Mar-02 $d$ \\
\hline 8444 & Popovich & & & $\mathrm{S}$ & $30-$ Sep-03 $e$ & $2001 X N 254$ & & & & $\mathrm{~S}$ & $14-A p r-02^{d}$ \\
\hline 17274 & 2000 LC16 & & & $\mathrm{D}$ & $10-$ Oct-00 $d$ & $2002 \mathrm{AA}$ & & & & $\mathrm{S}$ & 13-Jan-02 ${ }^{d}$ \\
\hline 18736 & $1998 \mathrm{NU}$ & & & $\mathrm{Sw}$ & 30-Jan-01 ${ }^{d}$ & $2002 \mathrm{AV}$ & & & & $\mathrm{S}$ & 13-Jan-02 ${ }^{d}$ \\
\hline 19127 & Olegefremov & & & Srw & $30-$ Sep-03 ${ }^{e}$ & & & & & & \\
\hline
\end{tabular}

${ }^{a}$ All visible data are from Bus (1999), Bus and Binzel (2002a) and Bus and Binzel (2002b) unless marked by a footnote. ${ }^{b}$ Visible data: Xu (1994); Xu et al. (1995). ${ }^{c}$ Visible data: (2000); Burbine and Binzel (2002). ${ }^{d}$ Binzel et al. (2004c) ${ }^{e}$ Visible data: This Work. 832, 03-Mar-05; 944, 14-June-01; 3402, 01-Sep-03; 6239 29-Dec-03; 6411, 29-Dec-03; 8444, 28-Dec-03; 19127 28-Dec-03; 66146, 3-Sep-03. All these observations were taken on telescope KPNO 4m except 944 on Magellan $6.5 \mathrm{~m} .{ }^{f}$ Visible data: Binzel et al. (2004b).

${ }^{g}$ Visible data: Binzel et al. (2001). ${ }^{h}$ Near-IR data: Binzel et al. (2004a). ${ }^{i}$ Near-IR data: Rivkin et al. (2005). 


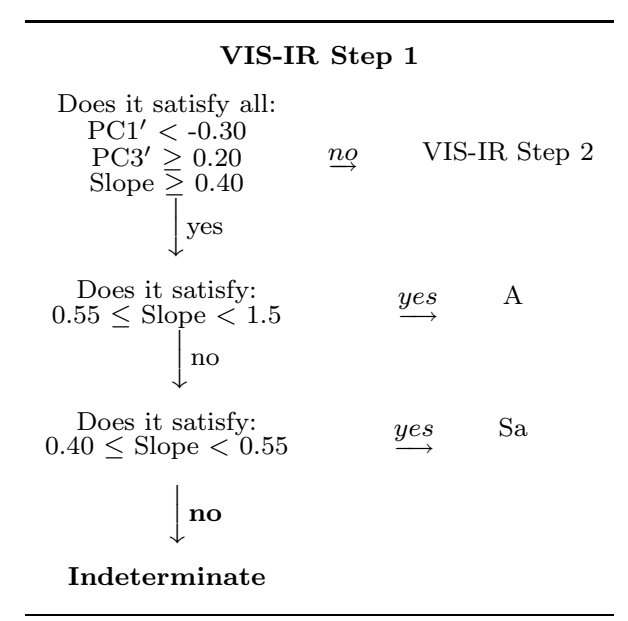

Appendix B. Visible - IR Flowchart 


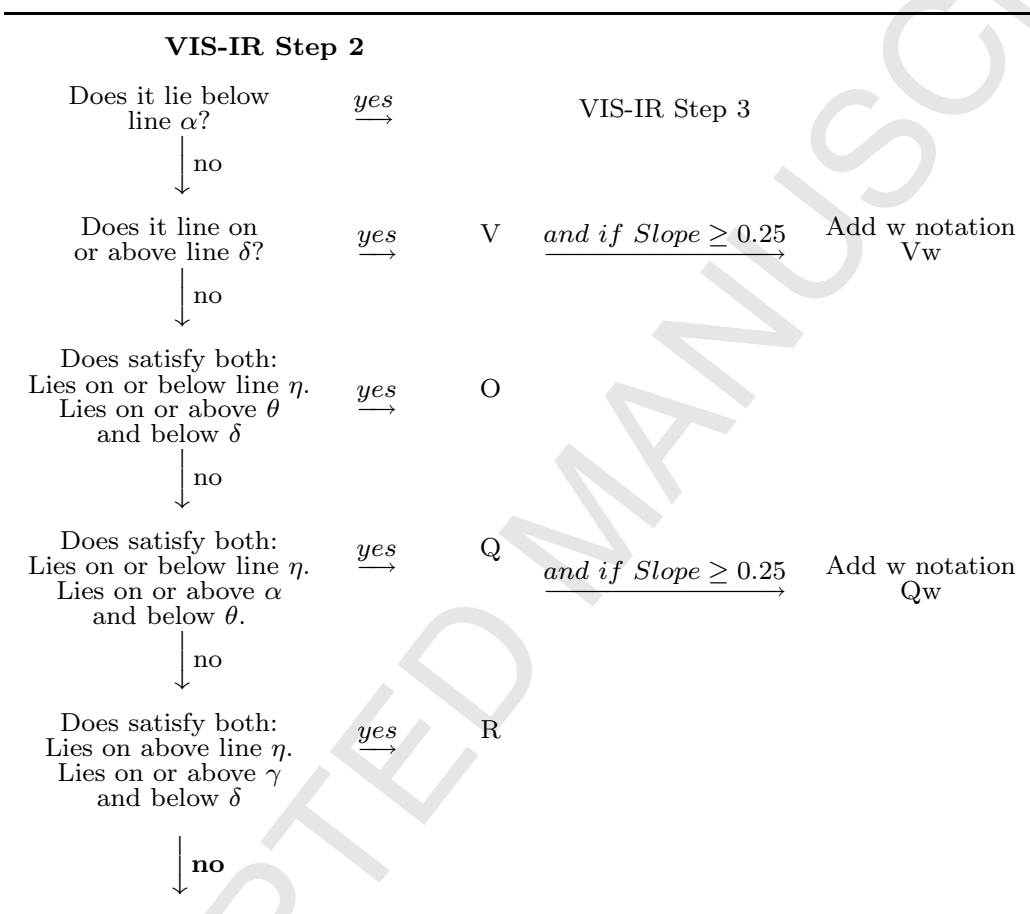

VIS-IR S-Complex 
VIS-IR Step 3

Does it satisfy both: $0.38 \leq$ Slope $<1.5$ $-0.44<\mathrm{PC} 1^{\prime}<0.4$ $\downarrow$ no

Does it satisfy all: $0.25<$ Slope $<0.38$ $-0.28<\mathrm{PC}^{\prime}<-0.20$ $-0.20<\mathrm{PC}^{\prime}<-0.12$ no

Does it satisfy both: $0.07<\mathrm{PC}^{\prime}<1.00$ $-0.5<\mathrm{PC}^{\prime}<-0.15$ no

Does it satisfy all: $-0.075<\mathrm{PC}^{\prime}<0.14$ $-0.20 \leq \mathrm{PC} 2^{\prime}<-0.10$ $-0.80<\mathrm{PC}^{\prime}<-0.10$ no

\section{$\stackrel{\text { yes }}{\longrightarrow}$ D A: Prominent 1- $\mu$ m feature.}

$\stackrel{\text { yes }}{\longrightarrow} \mathrm{T}$

$\stackrel{y e s}{\longrightarrow}$

L, Xe Xe: Shows feature at $0.49 \mu \mathrm{m}$.

yes $\mathrm{K}, \mathrm{Xe} \quad \mathrm{Xe}$ : Shows feature at $0.49 \mu \mathrm{m}$.

VIS-IR C- and X-Complexes 


\section{VIS-IR S-Complex}

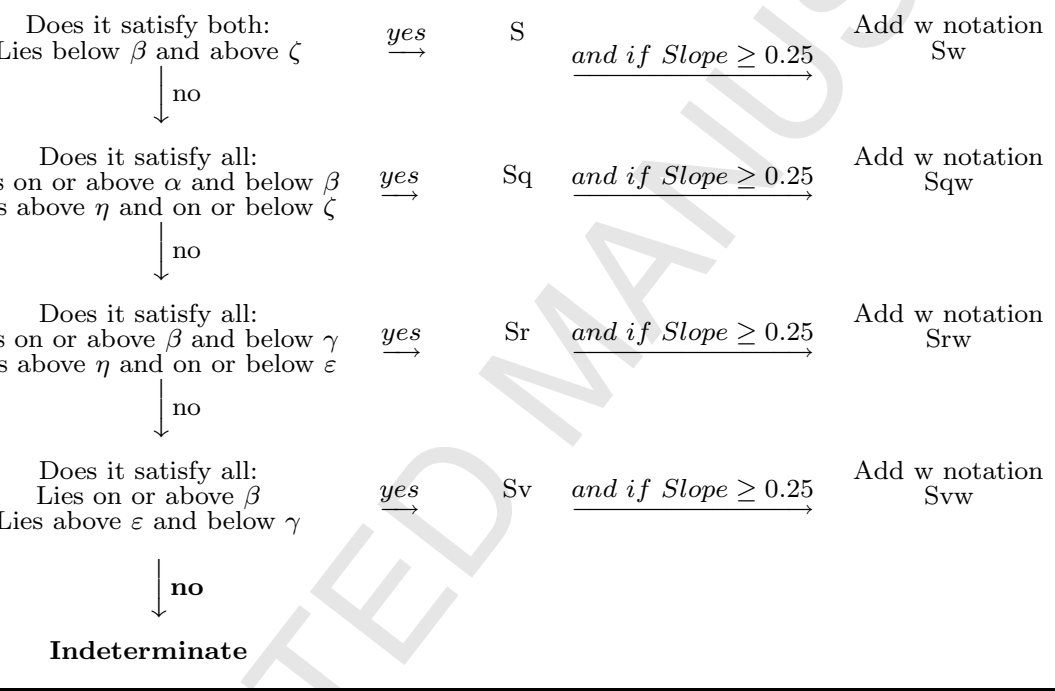




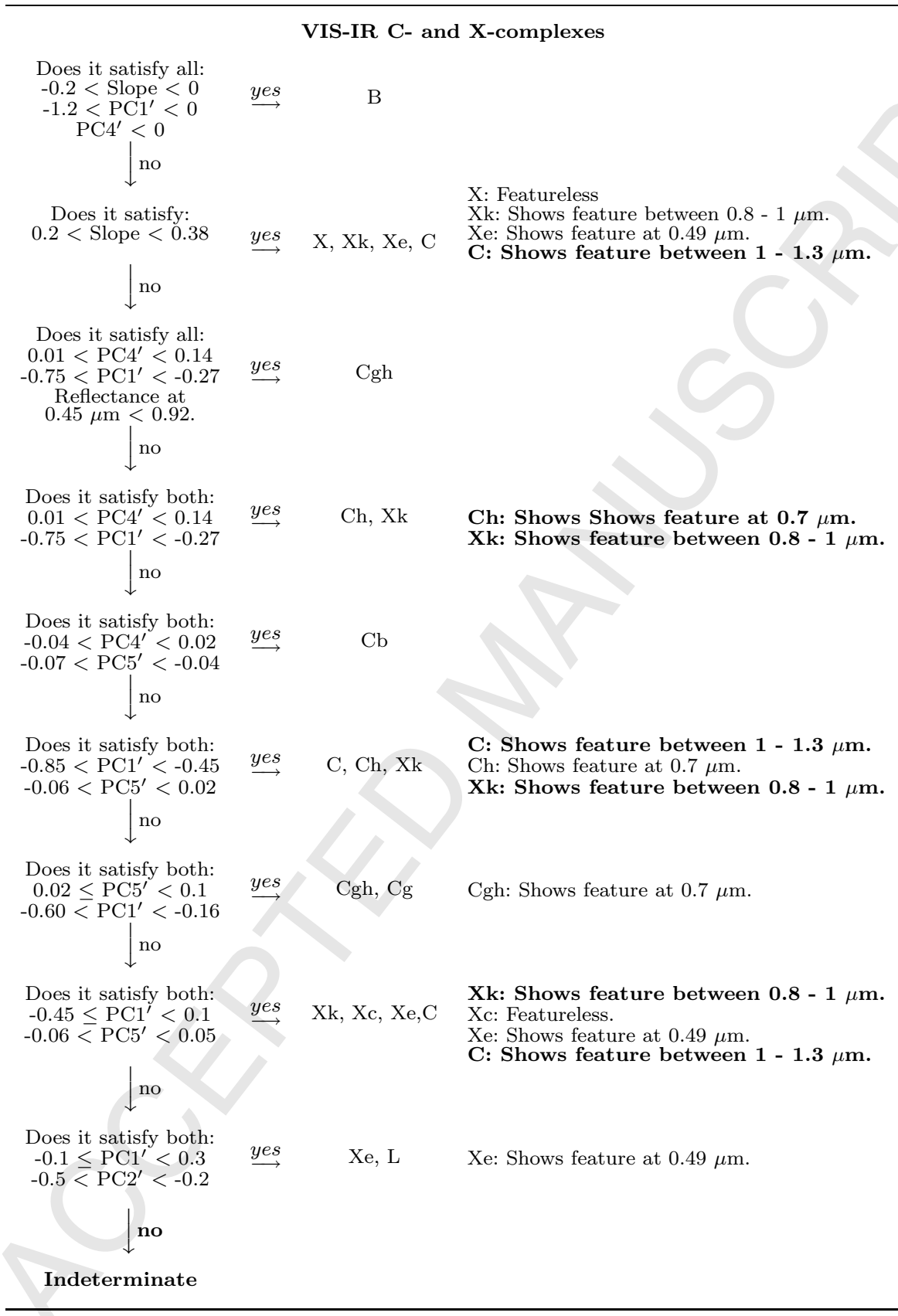




\begin{tabular}{ll|ll}
\hline & VIS-IR Checks $^{1}$ for Cg, Cgh, Ch, Xc, Xe, Xk & \multicolumn{2}{c}{ VIS-IR Equations } \\
\hline $\mathrm{Cg}$ & Strong UV absorption feature before $0.55 \mu \mathrm{m}$ & $P C 1^{\prime}=-3 P C 2^{\prime}-0.28$ & Line $\alpha$ \\
$\mathrm{Ch}$ & Moderately shallow absorption feature around $0.7 \mu \mathrm{m}$ & $P C 1^{\prime}=-3 P C 2^{\prime}+0.35$ & Line $\beta$ \\
$\mathrm{Cgh}$ & Strong UV absorption feature like Cg and $0.7-\mu \mathrm{m}$ & $P C 1^{\prime}=-3 P C 2^{\prime}+1.00$ & Line $\gamma$ \\
& feature like Ch (Reflectance at $0.45 \mu \mathrm{m}<0.92)$ & $P C 1^{\prime}=-3 P C 2^{\prime}+1.50$ & Line $\delta$ \\
$\mathrm{Xc}$ & Red and featureless with slight concave down curvature & $P C 1^{\prime}=\frac{1}{3} P C 2^{\prime}+0.50$ & Line $\varepsilon$ \\
$\mathrm{Xe}$ & Concave-up absorption feature before $0.55 \mu \mathrm{m}$ & $P C 1^{\prime}=\frac{1}{3} P C 2^{\prime}-0.10$ & Line $\zeta$ \\
$\mathrm{Xk}$ & Red shortward of $0.75 \mu \mathrm{m}$ and generally flat & $P C 1^{\prime}=\frac{1}{3} P C 2^{\prime}-0.50$ & Line $\eta$ \\
& longward of $0.75 \mu \mathrm{m}$ & $P C 1^{\prime}=-3 P C 2^{\prime}+0.70$ & Line $\theta$ \\
\hline
\end{tabular}

1 These spectral features are originally defined in Bus (1999) and Table 2 of Bus and Binzel (2002b). 
Appendix C. IR Flowchart

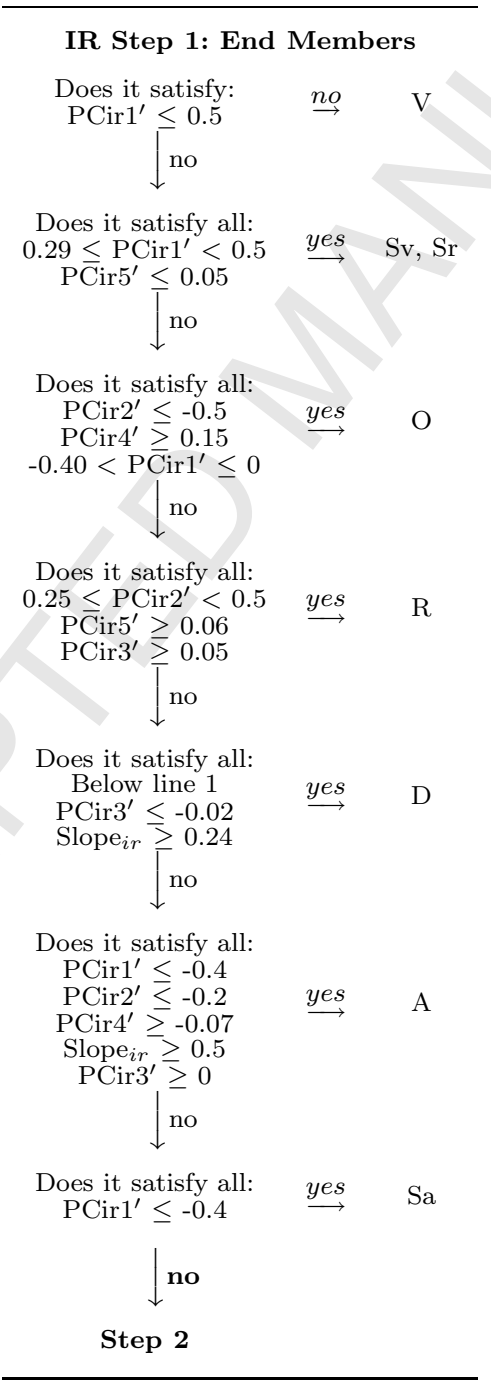


IR Step 2: S-complex

\begin{tabular}{|c|c|c|}
\hline $\begin{array}{c}\text { Does it lie on or } \\
\text { above line } 1 \text { and } 2 ? \\
\qquad \text { no }\end{array}$ & yes & $\mathrm{S}, \mathrm{Sr}, \mathrm{Sq}$ \\
\hline $\begin{array}{c}\text { Does it lie on or } \\
\text { above line } 1 \text { and } \\
\text { between line } 2 \text { and } 3 ?\end{array}$ & $\stackrel{\text { yes }}{\longrightarrow}$ & $\mathrm{S}, \mathrm{Sq}, \mathrm{Q}, \mathrm{L}, \mathrm{K}$ \\
\hline
\end{tabular}

Does it line on or above

line 1 and on or $\quad \stackrel{\text { yes }}{\longrightarrow} \mathrm{K}, \mathrm{L}, \mathrm{Sq}$

between line 3 and 4 ?

no

IR Step 3

IR Step 3: C- and X-complexes

Does it satisfy:

Below line 1 and on or $\stackrel{\text { yes }}{\longrightarrow} \mathrm{X}-$, C-complexes, $\mathrm{L}, \mathrm{K}, \mathrm{T}$ between 3 and 4 ?

$\downarrow$ no

Does it satisfy:

Below line 1 an between 2 and 3 ?

X-, C-complexes

no

Does it satisfy: $\quad$ yes $\quad \mathrm{C}, \mathrm{B}, \mathrm{L}, \mathrm{Cb}, \mathrm{X}$

Below line 1 and 4 ?

no

Indeterminate

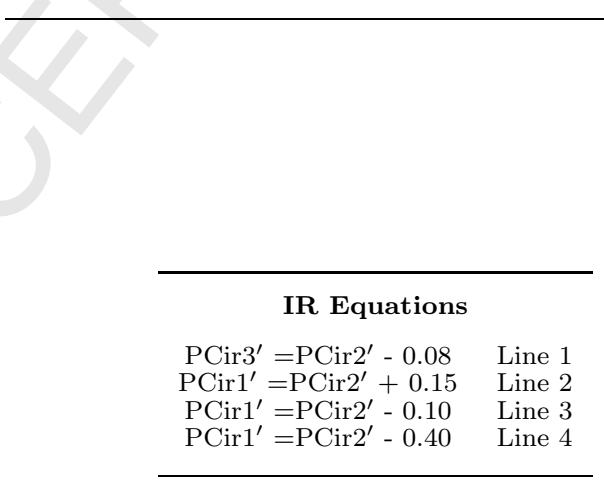


Appendix D

Reflectance Spectra for 371 Asteroids Defining this Taxonomy

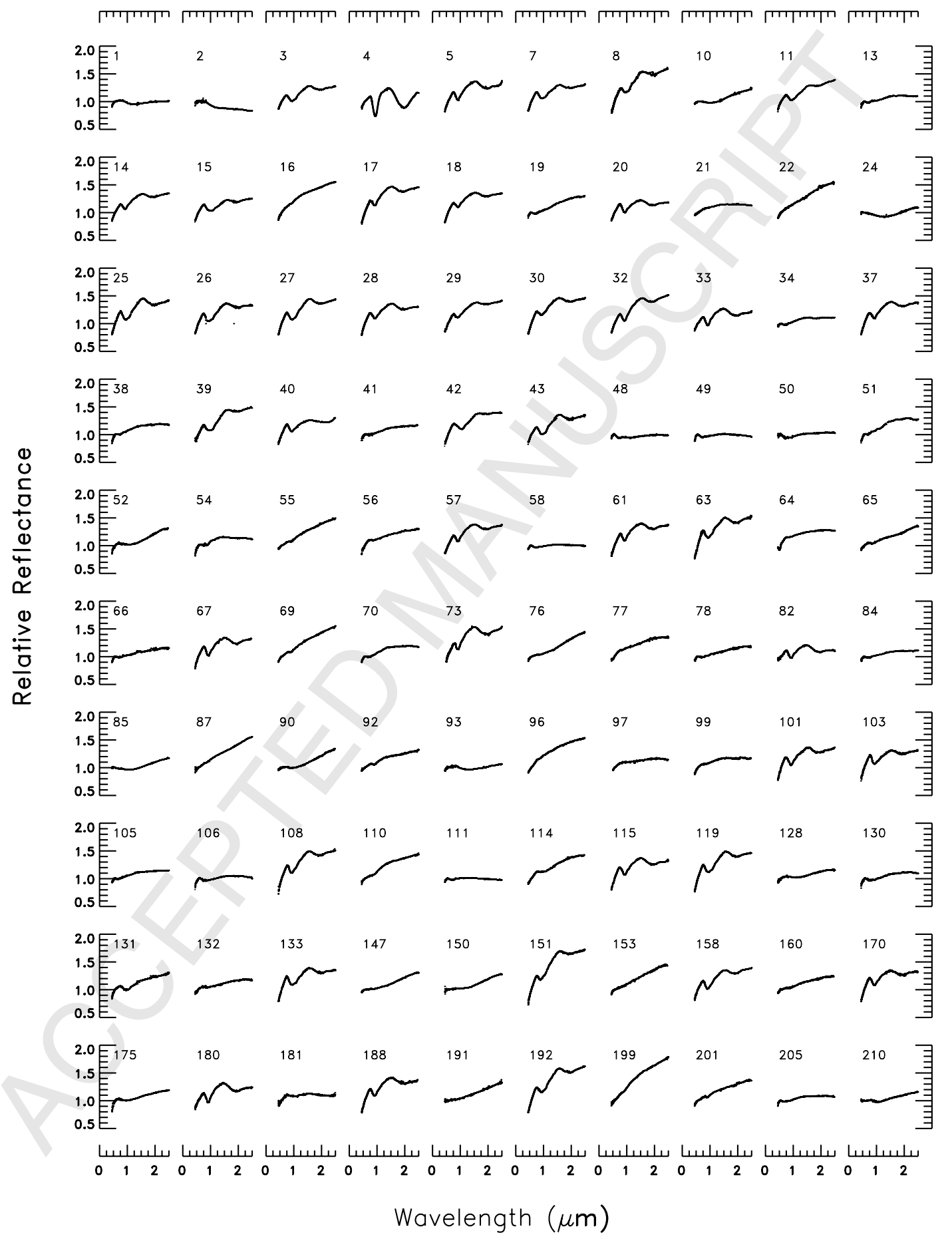


Reflectance Spectra for 371 Asteroids (cont.)

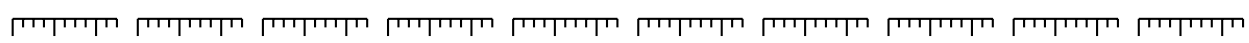

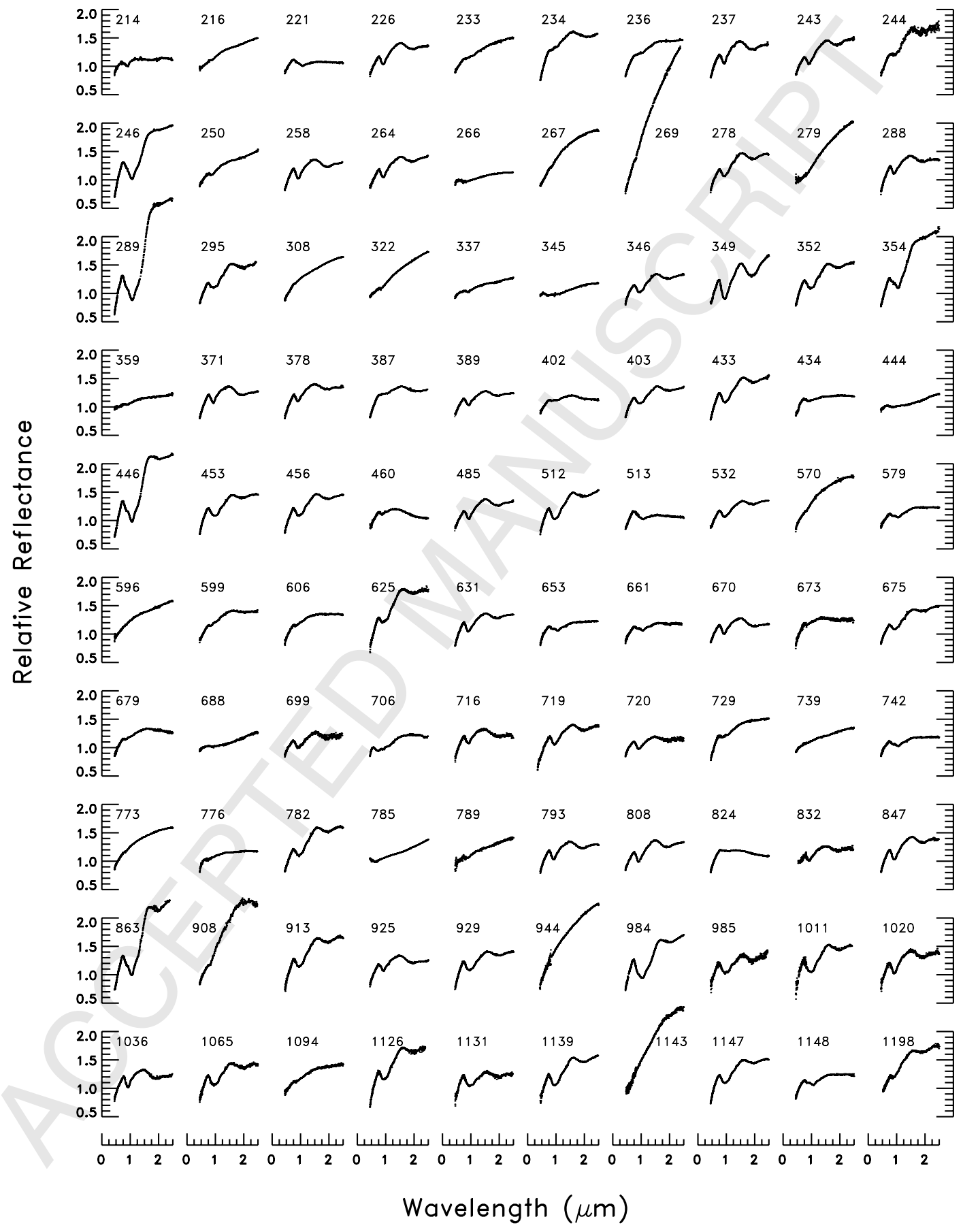


Reflectance Spectra for 371 Asteroids (cont.)

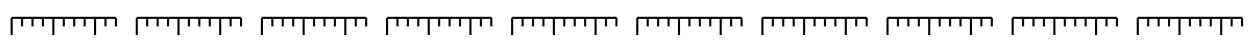
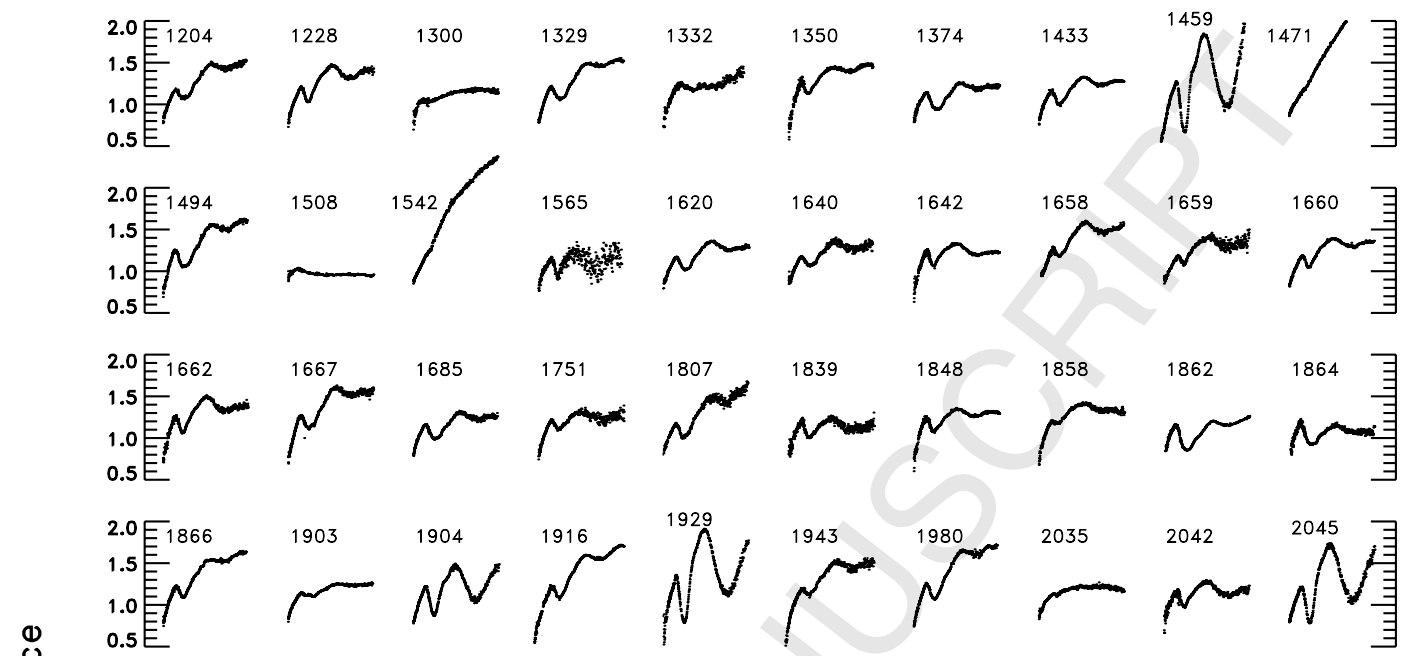

\begin{tabular}{l}
0 \\
0 \\
\multicolumn{1}{c}{} \\
0 \\
$\frac{1}{0}$ \\
0 \\
$\frac{1}{4}$ \\
0 \\
$\alpha$ \\
0 \\
$\geq \frac{1}{0}$ \\
$\frac{0}{0}$ \\
$\alpha$
\end{tabular}
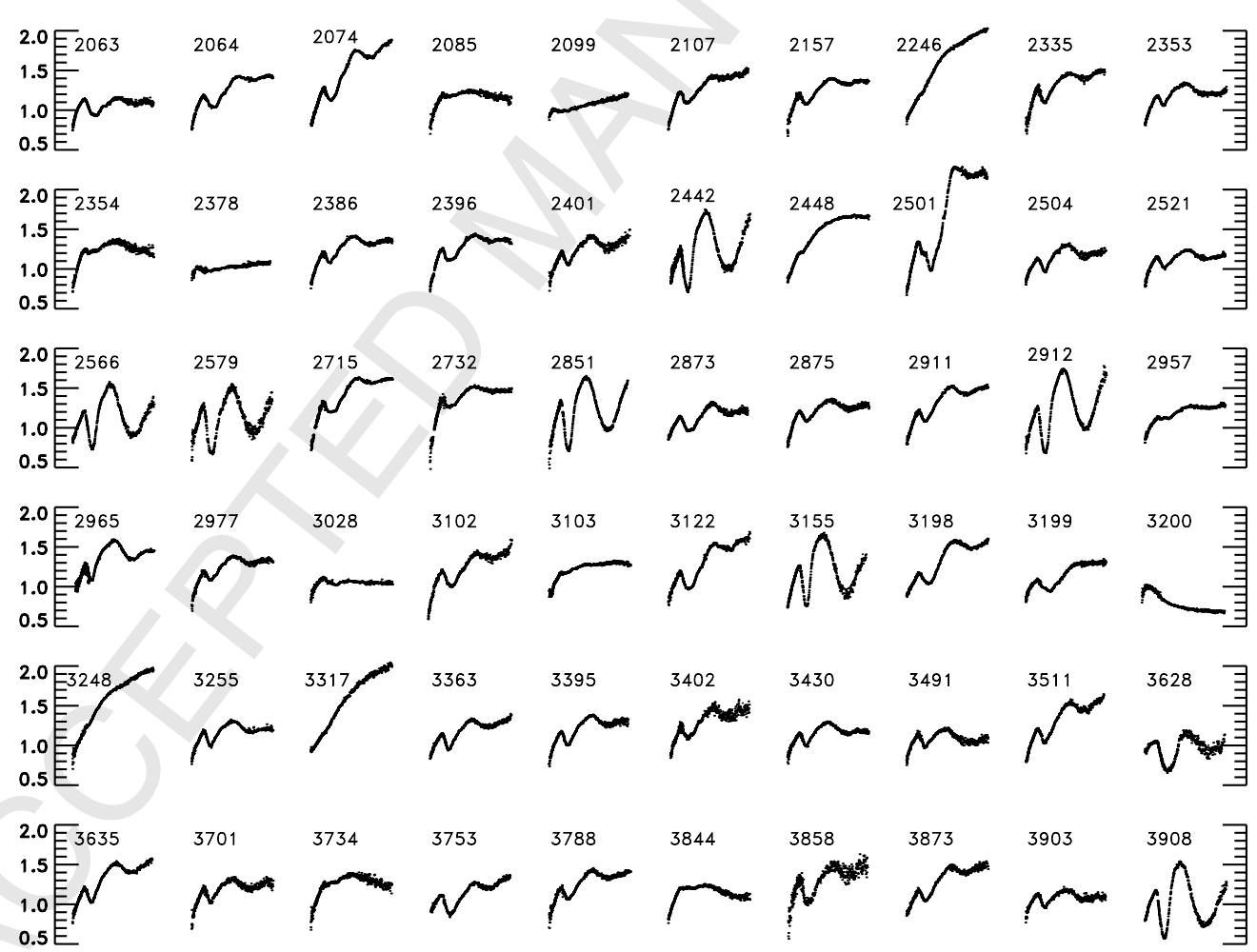

سلسلسا بلس بلسا

Wavelength $(\mu \mathrm{m})$ 
Reflectance Spectra for 371 Asteroids (cont.)

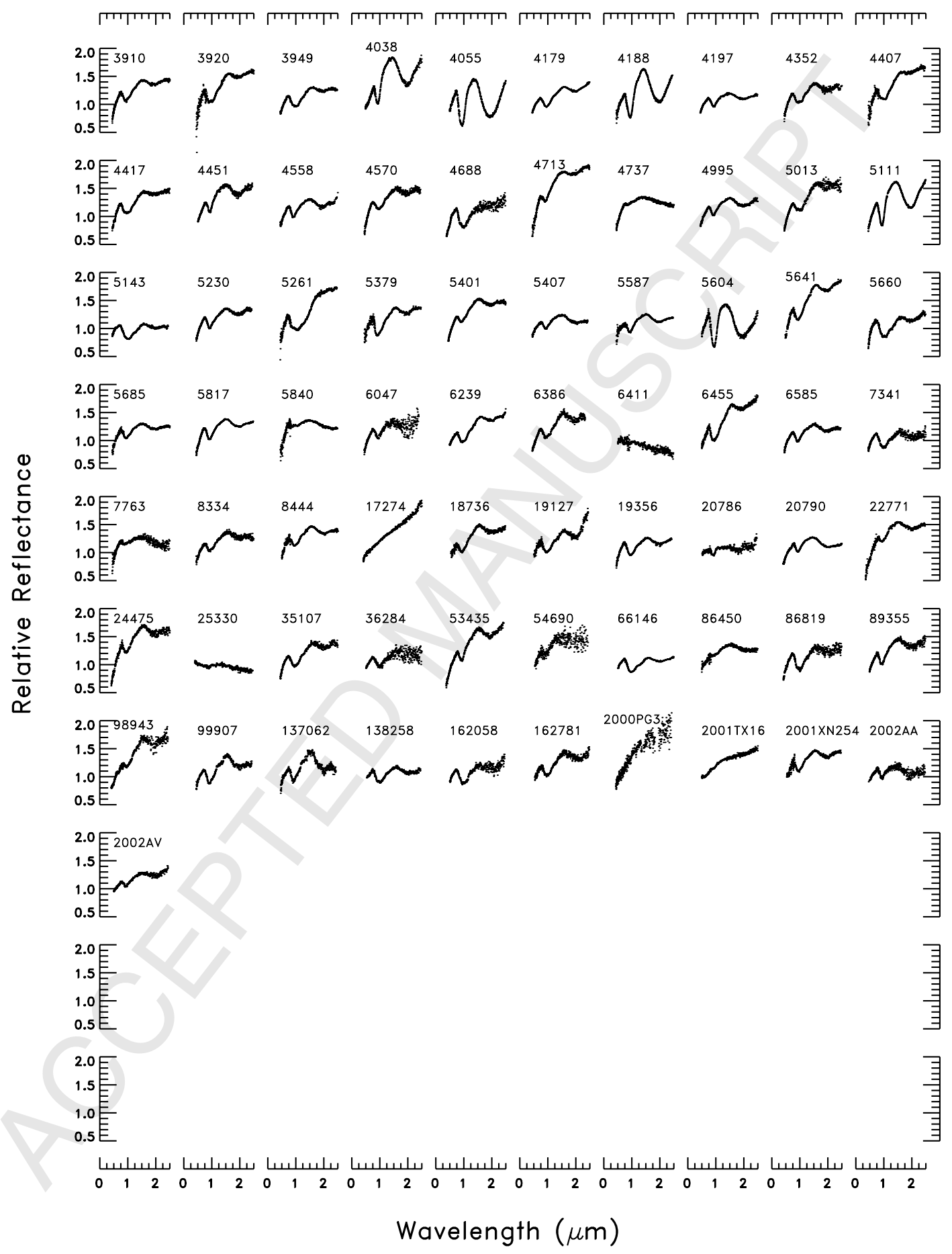

